Document downloaded from:

http://hdl.handle.net/10251/169182

This paper must be cited as:

Olmeda, P.; Martín, J.; Arnau Martínez, FJ.; Artham, S. (2020). Analysis of the energy balance during World harmonized Light vehicles Test Cycle in warmed and cold conditions using a Virtual Engine. International Journal of Engine Research. 21(6):1037-1054. https://doi.org/10.1177/1468087419878593

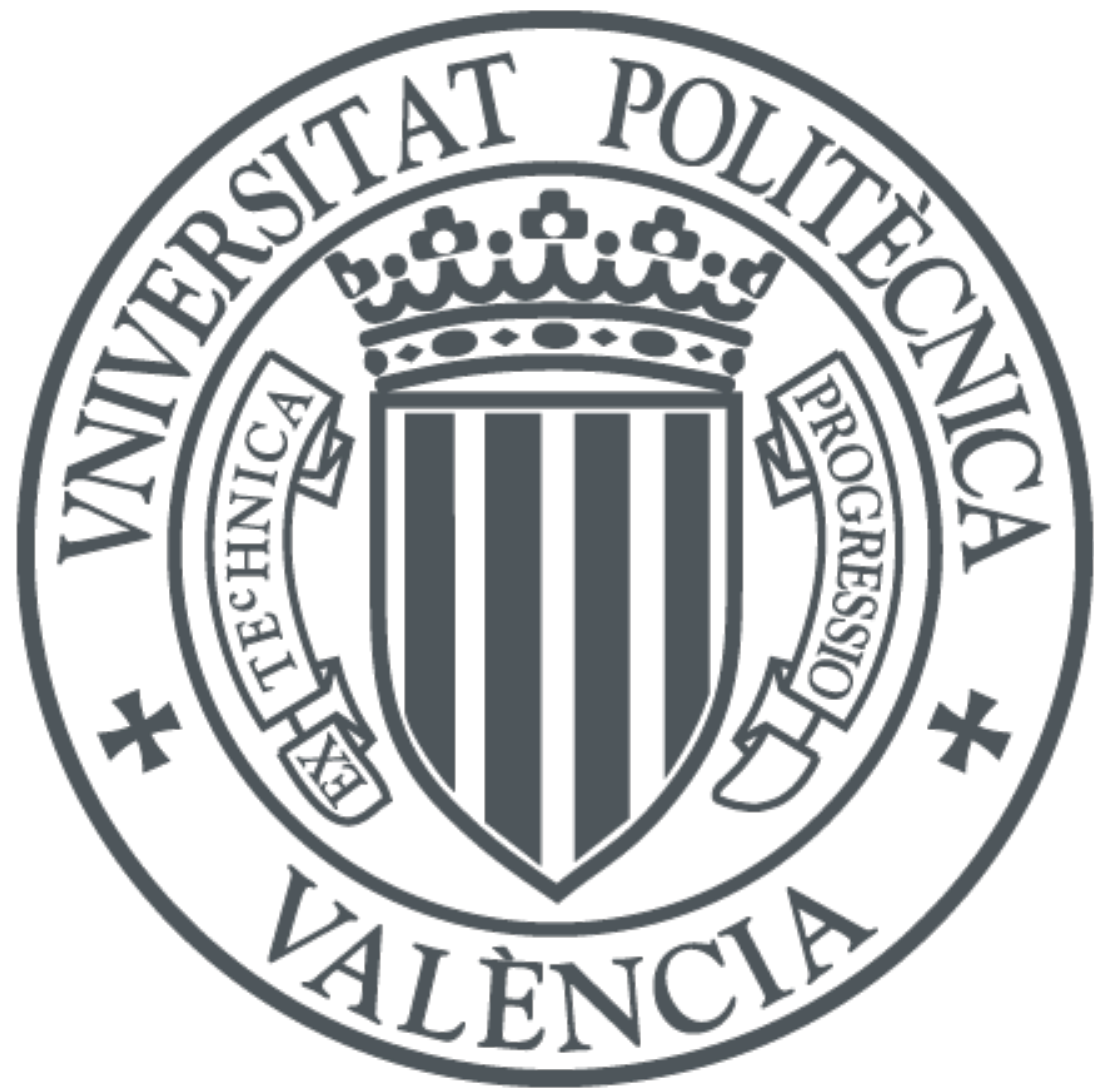

The final publication is available at

https://doi.org/10.1177/1468087419878593

Copyright SAGE Publications

Additional Information

This is the author's version of a work that was accepted for publication in International Journal of Engine Research. Changes resulting from the publishing process, such as peer review, editing, corrections, structural formatting, and other quality control mechanisms may not be reflected in this document. Changes may have been made to this work since it was submitted for publication. A definitive version was subsequently published as https://doi.org/10.1177/1468087419878593. 


\title{
Analysis of the energy balance during WLTC in warmed and cold conditions using a Virtual Engine
}

\author{
Pablo Olmeda, Jaime Martín ${ }^{\star}$, Francisco J. Arnau and Sushma \\ Artham
}

\begin{abstract}
In recent years, the interest on transient operation and real driving emissions have increased because of the global concern about environmental pollution that has led to new emissions regulation and new standard testing cycles. In this framework, it is mandatory to focus the engines research on the transient operation, where a Virtual Engine has been used to perform the Global Energy Balance (GEB) of a 1.6 L Diesel engine during a World harmonized Light vehicles Test Cycle (WLTC). Thus, the energy repartition of the chemical energy has been described with warmed engine and cold start conditions, analyzing in detail the mechanisms affecting the engine consumption. The fist a nalysis f ocusses o $n$ t he "delay" e ffect a ffecting the instantaneous energy balance due to the time lag between the in-cylinder processes and pipes: as main conclusion it is obtained that it leads to an apparent unbalance than can reach more than $10 \%$ of the cumulated fuel energy at the beginning of the cycle, becoming later negligible. Energy split analysis in cold starting WLTC shows that in this conditions the energy accumulation in the block is a key term at the beginning (about 50\%) that diminishes its weight until about $10 \%$ at the end of the cycle. In warmed conditions energy accumulation is negligible but the heat transfer to coolant and oil are higher than in cold starting (21\% vs $28 \%)$. The lower values of the mean brake efficiency a t the beginning of the W LTCs ( only a bout $20 \%$ ), is affected, especially in cold starting, by the higher mechanical losses due to the higher oil viscosity, and the heat rejection from the gases. The friction plays an important role only during the first half of the cycle, with a percentage of about $65 \%$ of the total mechanical losses and $10 \%$ of the total fuel energy at the end of the WLTCs. However, at the end of the cycle it does not affect dramatically the mean brake efficiency which is about $31 \%$ both in cold starting and warmed WLTC.
\end{abstract}




\section{Keywords}

Transient, Global Energy Balance, Virtual Engine, WLTC

\section{Corresponding author:}

Martín Díaz Jaime, CMT-Motores Térmicos, Universitat Politècnica de València, Camino de Vera s/n. 46022 València, Spain, www.cmt.upv.es, Tel: +34963877650, fax: +34963877659

Email: jaimardi@mot.upv.es 


\section{Nomenclature}

$\begin{array}{ll}\text { DI } & \text { Direct Ignition } \\ \text { ECU } & \text { Engine control unit } \\ \text { EGR } & \text { Exhaust gas recirculation } \\ \text { GEB } & \text { Global Energy Balance } \\ \text { HPEGR } & \text { High pressure exhaust gas recirculation } \\ \text { HSDI } & \text { High speed direct injection } \\ \text { ICE } & \text { Internal combustion engines } \\ \text { IMEP } & \text { Indicated mean effective pressure } \\ \text { LPEGR } & \text { Low pressure exhaust gas recirculation } \\ \text { 1D } & \text { One-dimensional } \\ \text { VEMOD } & \text { Virtual Engine Model } \\ \text { WLTC } & \text { World harmonized light vehicles test cycle } \\ \text { WLTP } & \text { World harmonized light vehicles test procedure } \\ \text { OD } & \text { Zero-dimensional }\end{array}$

\section{Introduction}

Current internal combustion engines (ICE) has to overcome several problems and demands, one of the most important challenges include the improvement of fuel economy without compromising the engine performance, along with reduced engine emissions at wide range of operating conditions. Thus, automotive manufacturers are facing many challenges to meet government regulations while satisfying the demands of the consumer on outstanding performance, high fuel economy and low cost by means of a number of different approaches. It should also be noticed that even though during the last decades ICEs have been forced to an impressive reduction in pollutant emissions of around 95\% in European emission regulations (Euro 1-6), the restrictions to the emissions and consumption will continue in the next years. In this scenario, even though new power plants are being explored for transport applications, the ICE is estimated to continue being the main power plant during the next decades both as main power plant (specially for middle size and large engines) or as part of hybrid power plants in smaller vehicles.

Some years ago, the trend for studying internal combustion engines operation was focused on the steady-state performance, with low attention paid to the transient operation. However, the most of new driving cycles involves transient conditions and it is not usual running at stationary conditions in real-world engine operation ${ }^{1}$. Moreover, transient engine operation contributes much more to the total amount of emissions over a driving cycle than steady-state engine operation ${ }^{2}$.

In recent years, the interest on transient operation and real driving emissions have increased because of the global concern about environmental pollution that has led to important changes in the regulation. The increasingly rigorous regulation on pollutants and $\mathrm{CO} 2$ emissions have led to the World harmonized Light vehicles Test Procedure (WLTP) ${ }^{3}$, which came into force in September 2017 in Euro 6d-Temp, which has more 
realistic testing conditions including extended ambient temperature ranges covering low temperature conditions ${ }^{4}$. This WLTC is forcing the automotive industry to optimize different technologies such as engine rightsizing, turbocharging, direct injection, flexible valve actuation or after-treatment systems that are standard solution for emissions reduction and fuel economy improvement of passenger cars and light-duty trucks ${ }^{4,5}$.

When facing the engine behavior in a WLTC, the ambient and fluid (coolant and oil) temperatures are important because they will affect heat rejection and in-cylinder conditions, thus affecting combustion and emissions formation and mechanical losses ${ }^{6}$. Moreover, when changing the fluids temperatures the engine calibration change the settings in order to adapt the engine performance. As an example, when in cold start friction increases due to the higher oil viscosity, the fuel mass injected need to be increased and hence the air management settings also change. Heat transfer in the chamber is higher at cold start due to the low fluid and wall temperatures. Regarding emissions, in the cold start, $\mathrm{CO}$ are higher compared to warmed operation and NOx emissions, which are very dependent on temperature, are expected to gradually increase ${ }^{1}$, when engine temperature increases. Also, the thermal state of the engine is going to be an issue when dealing with the after-treatment performance because the chemical reactions in this elements requires reaching an activation temperature.

Since understanding and assessing different technologies in transient operation has became a key issue to face emissions formation and consumption, experimental and simulation methodologies in this field have increased their importance. In order to evaluate the benefits of a specific engine strategy, performing a Global Energy Balance (GEB $)^{7,8}$ is a useful methodology to identify the paths followed by the chemical energy, thus contributing to understand the mechanism affecting the engine consumption. The identification of the energy repartition allows determining the effect of different processes inherent to ICE operation such as cooling, lubricating, fuel injection and air management. Some works dealing with experimental GEB can be found in the literature ${ }^{9-11}$. They are performed to assess the effect of fuels blends ${ }^{12}$ and alternative fuels ${ }^{10}$ or the heat transfer variation by insulating the combustion chamber walls ${ }^{13}$ or to analyze the engine operating conditions in the energy repartition ${ }^{14,15}$. Generally, the energy balance is carried out by considering the brake power, mechanical losses and the exhaust gas energy. It can be performed in a more detail way by considering the heat transfers in the coolant and oil ${ }^{14}$. The terms that account for energy losses with minor impact such as un-burned fuel, heat rejection to the ambient and blow-by enthalpy ${ }^{13}$ use to be neglected.

Transient operation is characterized by quick changes in the operating conditions, which can be particularly demanding in terms of engine response and control that requires specific simulation analysis to improve and accelerate the engine development. In this framework, the use of $0 \mathrm{D} / 1 \mathrm{D}$ tools to simulate the complete engine behavior (system modeling) has shown to be really useful. The theoretical modeling is a useful way to predict trends and allows simulating multiple engine configurations at a lower cost than the experimental work, thus providing guidelines for further engine improvement. Few works dealing with the complete simulation of the engine energy balance can be found in the literature; the available ones show different points of view that can range from performing the analysis on the combustion chamber ${ }^{16,17}$, simulating the heat transfer at 
different engine sub-systems ${ }^{18}$ or focusing in specific process such as engine cooling ${ }^{19}$. However, the complex phenomena involved in real operation makes difficult to face accurately the simulation of the complete system. For this reason, it is usual to combine simulation with experimental information. An example of a through and integral analysis of the energy balance combining experimental and simulated information was provided in a previous work ${ }^{20}$.

However, all the works described are focused on the engine operation in stationary conditions. In fact, there is a lack of works dealing with the GEB in transient operation and only a limited number can be found in the literature ${ }^{21}$. As an example, Romero et $\mathrm{al}^{21}$ performed the thermal balance of a Diesel engine under transient conditions, exploring the instantaneous energy split during real driving conditions, with the objective of showing the dynamics of energy split, and providing an estimate of the energy losses averaged along the cycle.

To fill this gap, this work is aimed at analyzing the energy balance in transient operation with different fluid temperatures. Thus the study will focus on the WLTC analysis in a $1.6 \mathrm{~L}$ diesel engine with two initial conditions: warmed engine and cold start (with an initial temperature of $20^{\circ} \mathrm{C}$ ). The methodology followed will be basically based on the use of a 0D-1D modelling tool called VEMOD ${ }^{4}$ that is previously calibrated in stationary conditions and will be validated in the WLTC by comparing some key variables to characterize the thermal behavior of the engine. Once the model is validated, a complete discussion of the energy split will be provided, using the tool to calculate the different terms that can hardly be obtained experimentally. The discussion includes the comparison of the energy split at cold conditions with warmed conditions.

\section{Experimental and modeling tools}

\section{Experimental tool}

In order to reproduce the repartition of the energy at each sub-system in realistic operating conditions, the research was carried out in a multi-cylinder, HSDI Diesel engine. The engine is a 1.6 four-stroke engine compliant with Euro 5 emissions regulations. The specifications of the engine can be found in Table 1. The engine includes an electro valve that blocks coolant flow through the engine block during engine warming, which reduces the warm-up time. The intake air to the cylinders is cooled by air-water heat exchangers ${ }^{4}$.

The test cell as shown in Figure 1, is fully equipped to measure main operation mean variables (e.g. air and fuel mass flows, temperature and pressure at intake and exhaust lines, etc.), some liquids .), oil and coolant temperatures, coolant mass flows and incylinder pressures in the four cylinders. It includes a Horiba MEXA exhaust gas analyzer along with an AVL439 Opacimeter. Table 2 summarizes the relevant instrumentation used for this study. Mean variables were acquired at a frequency of $10 \mathrm{~Hz}$ with Horiba Stars test automation system, while instantaneous signals were measured at $0.5^{\circ}$.

The stationary tests for calibration were performed at 26 operating points with low to high engine speed ( $850 \mathrm{rpm}$ to $4000 \mathrm{rpm}$ ) and from low to high load (idle to full load). 
Table 1. Engine specifications

\begin{tabular}{|l|l|}
\hline Type & HSDI Diesel engine \\
\hline Displacement & $1598 \mathrm{~cm}^{3}$ \\
\hline Bore & $80 \mathrm{~mm}$ \\
\hline Stroke & $79.5 \mathrm{~mm}$ \\
\hline $\begin{array}{l}\text { Compression } \\
\text { ratio }\end{array}$ & $14.5: 1$ \\
\hline $\begin{array}{l}\text { Number of } \\
\text { valves }\end{array}$ & $4 /$ cylinder \\
\hline $\begin{array}{l}\text { Number of } \\
\text { cylinders }\end{array}$ & 4 \\
\hline $\begin{array}{l}\text { Air } \\
\text { management }\end{array}$ & VGT, HP-EGR, LP-EGR \\
\hline $\begin{array}{l}\text { Maximum power } \\
\text { @ speed }\end{array}$ & $96 \mathrm{~kW}$ @ 4000 rpm \\
\hline $\begin{array}{l}\text { Maximum torque } \\
\text { @ speed }\end{array}$ & $320 \mathrm{Nm}$ @ $1750 \mathrm{rpm}$ \\
\hline
\end{tabular}

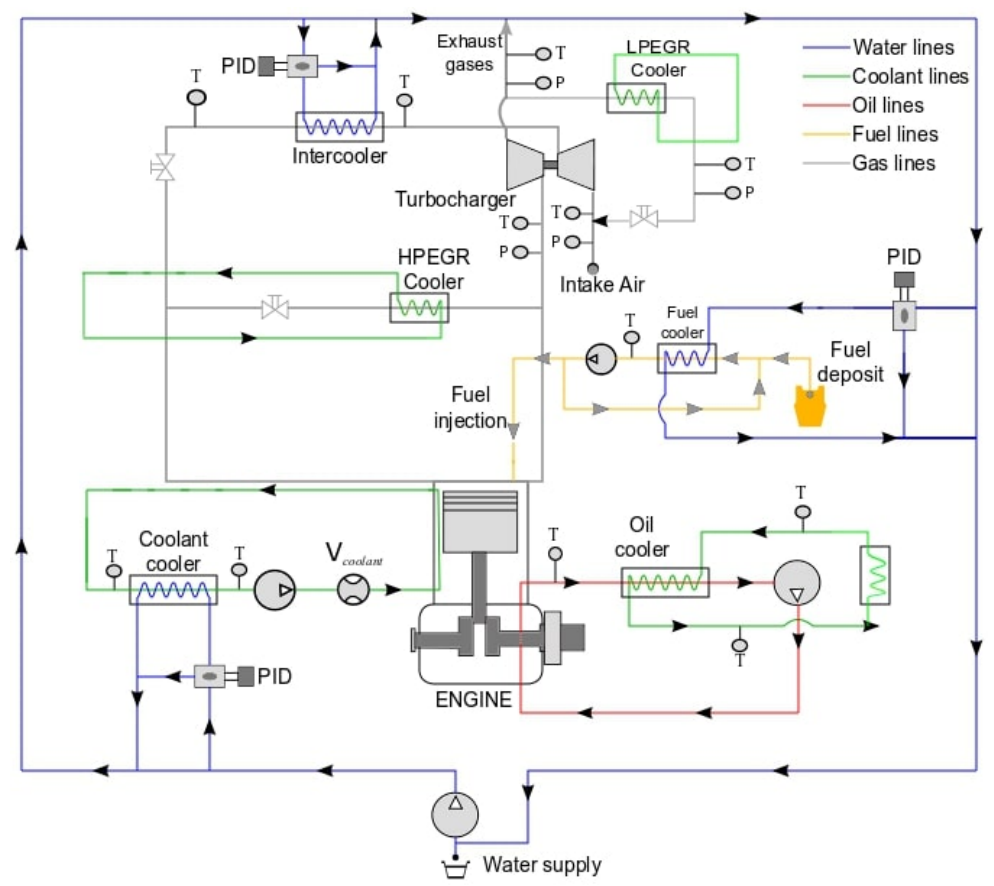

Figure 1. Test cell scheme 
Table 2. Test cell instrumentation

\begin{tabular}{|l|l|l|l|}
\hline Variable & Instrument & Range & Accuracy \\
\hline Crank angle & Encoder & $0-360^{\circ}$ & $\pm 0.02^{\circ}$ \\
\hline Torque & Dynamometer & $0-400 \mathrm{Nm}$ & $\pm 0.5 \mathrm{Nm}$ \\
\hline Gas/wall temperature & k-type thermocouple & $70-1520 \mathrm{~K}$ & $\pm 2 \mathrm{~K}$ \\
\hline Air mass flow & Sensyflow DN80 & $0-1700 \mathrm{~kg} / \mathrm{h}$ & $\pm 2 \%$ \\
\hline Coolant flow & Krohne 4010 Optiflux & $4.5-90 \mathrm{~L} / \mathrm{min}$ & $\pm 0.5 \%$ \\
\hline Oil pressure & $\begin{array}{l}\text { Piezoresistive } \\
\text { transducer }\end{array}$ & $0-10 \mathrm{bar}$ & \pm 25 mbar \\
\hline In-cylinder pressure & AVL GH13P & $0-200 \mathrm{bar}$ & Linearity $0.3 \%$ \\
\hline
\end{tabular}

Some of them were measured at low temperature cold conditions $\left(-7^{\circ} \mathrm{C}\right)$. They cover a wide range of the engine map and testing points belonging to the WLTC as shown in Table 3. Engine operating parameters were set according to the calibration included in the engine control unit (ECU).

Table 3. Stationary tests performed

\begin{tabular}{|l|l|}
\hline Engine speed in rpm & Load in \% \\
\hline 1000 & Motoring \\
\hline 2000 & Motoring \\
\hline 3000 & Motoring \\
\hline 4000 & Motoring \\
\hline 850 & idle \\
\hline 1000 & $21,44,66,88$ \\
\hline 1250 & $13,26,50,76,100$ \\
\hline 1500 & $11,25^{*}, 50,75^{*}, 100$ \\
\hline 2500 & $25,50,75,100$ \\
\hline 3500 & $25^{*}, 50,75,100$ \\
\hline
\end{tabular}

* Both conventional and Cold ambient conditions $\left(-7^{\circ} \mathrm{C}\right)$

Table 4. Initial temperatures in the WLTC tests performed

\begin{tabular}{|l|c|c|c|c|}
\hline $\begin{array}{c}\text { Test } \\
\text { conditions }\end{array}$ & $\begin{array}{c}\text { Room } \\
\text { temperature }\end{array}$ & $\begin{array}{c}\text { Initial block } \\
\text { temperature }\end{array}$ & $\begin{array}{c}\text { Initial Coolant } \\
\text { temperature }\end{array}$ & $\begin{array}{c}\text { Initial Oil } \\
\text { temperature }\end{array}$ \\
\hline Cold start & $20^{\circ} \mathrm{C}$ & $20^{\circ} \mathrm{C}$ & $20^{\circ} \mathrm{C}$ & $20^{\circ} \mathrm{C}$ \\
\hline Warmed start & $20^{\circ} \mathrm{C}$ & $\approx 80^{\circ} \mathrm{C}$ & $\approx 80^{\circ} \mathrm{C}$ & $\approx 85^{\circ} \mathrm{C}$ \\
\hline
\end{tabular}

The transient analysis is performed in two WLTC tests, measured with warmed engine and cold start conditions(starting at $20^{\circ} \mathrm{C}$ ). Table 4 summarizes the different engine 
temperatures at these conditions at the beginning of the test. Three repetitions of each WLTC and stationary point were measured.

\section{Predictive tool}

The Virtual Engine Model (VEMOD) ${ }^{4}$ is a standalone tool aimed at simulating new standard testing cycles. This computational tool was developed as a response to limiting requirements of new standards, closer to real-world driving conditions. VEMOD is able to predict engine performance and emissions along with the complete thermo and fluid dynamic condition in the different fluid circuits including gas and liquids (coolant and oil). It covers the calculation of different processes as shown in Figure 2. Various sub-models are used to obtain heat rejection to chamber walls, brake power, perform calculations of flow properties, prediction of various emissions, in-cylinder conditions based on combustion process, heat transfer and wall temperatures. The core of VEMOD is the combustion model, a 1D model based on the concept of Apparent Combustion Time $(\mathrm{ACT})^{22,23}$, which provides VEMOD with the capacity of predicting heat release rate and emissions through the calculation of local conditions in the combustion chamber. It is an upgraded version of a combustion model developed at the research group ${ }^{24}$. The whole set of sub-models, marked with a blue box in Figure 2, make up the engine model. The red boxes in Figure 2 represent the different control sub-models, which have been developed in Matlab/Simulink ${ }^{4}$.

VEMOD will be used to model the different energy terms to complete the energy balance of the system.

\section{Combustion diagnosis tool}

A combustion diagnosis tool called CALMEC ${ }^{7,25}$, developed at CMT-Motores Térmicos was used to calculate the heat release and to calibrate the in-cylinder heat transfer in VEMOD $^{25-27}$, based on the experimental measurements in stationary conditions.

\section{Methodology}

The scheme of the methodology followed is shown in Figure 3. It was structured as follows:

1. The stationary and WLTC transient tests were conducted in the installation described in the experimental tool section. The parameters required for analyzing were measured as described.

2. Calibration of the combustion and emission sub-models, in-cylinder heat transfer and mechanical losses were carried out using the set of stationary points and the characterization methodology described by Benajes et al ${ }^{26}$.

3. The VEMOD validation in transient test is performed using experimental data of the evolution of fluid temperatures and brake torque. 


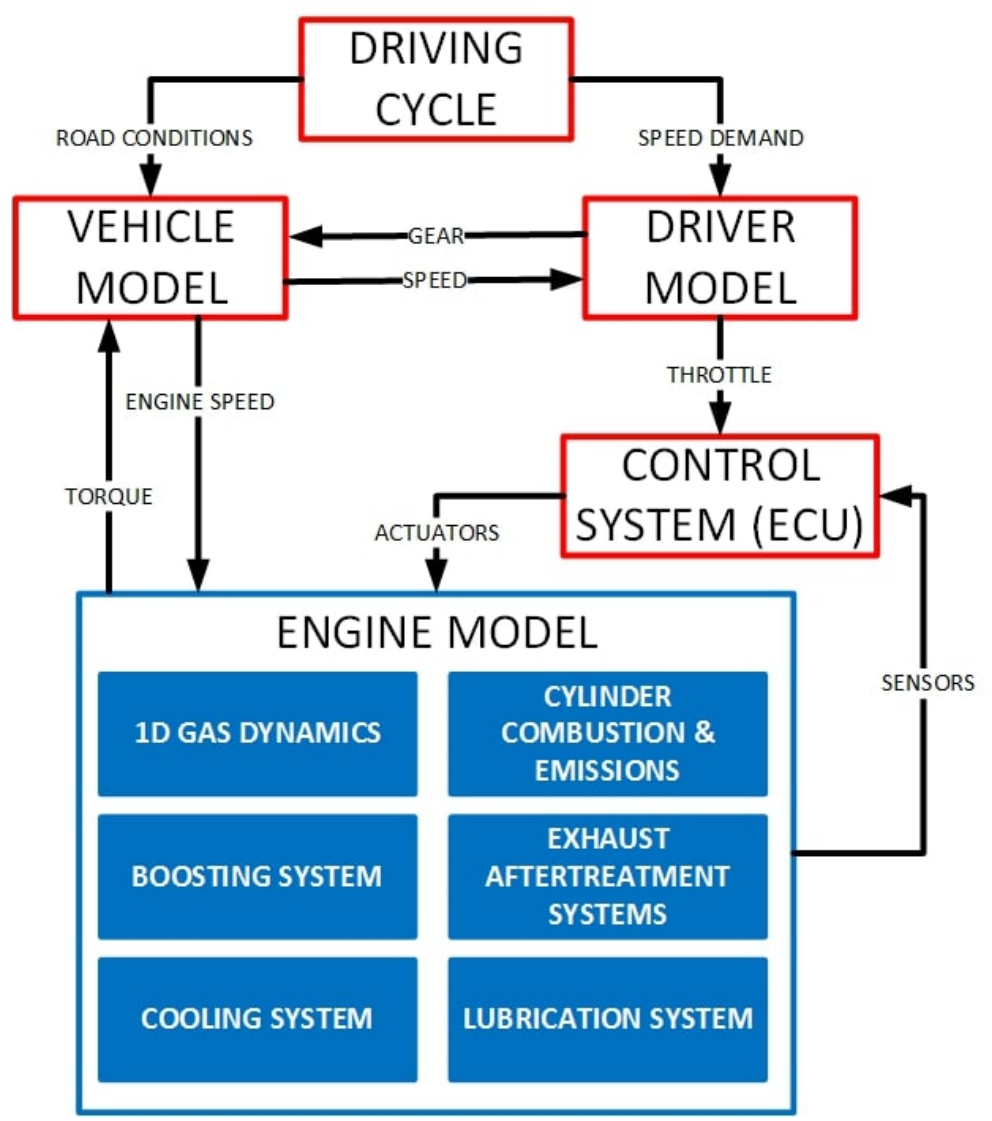

Figure 2. Flow-chart of Virtual Engine Model (VEMOD) modules

4. An extensive analysis of the energy repartition was carried out to assess the effect of different variables on the Global Energy Balance and engine performance. GEB during WLTC was obtained at different thermal conditions, using some experimental data to set target conditions during simulation, as detailed below.

The above mentioned methodology allows achieving the objective of analyzing the GEB in transient tests at different thermal conditions.

For the calculation of both stationary points and the WLTC, the experimental values of air mass flow, fuel mass, fuel rail pressure, engine speed, injection settings and boost pressure were set as targets or directly imposed at every instant. 


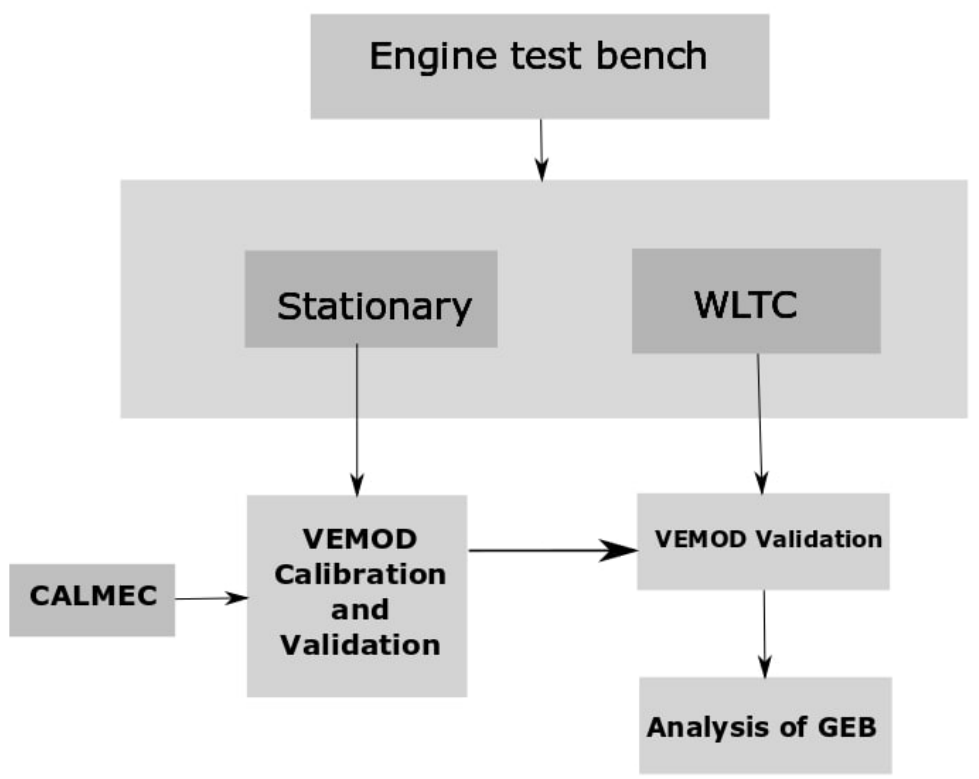

Figure 3. Methodology

\section{Global Energy Balance (GEB) description}

The basis of the analysis is the first law of thermodynamics. There must be an energy balance between engine input (mainly fuel chemical power) and output. Different paths followed by energy terms and energy distribution are represented in Figure 4. Where, all the energy transformations taking place in a diesel engine, are taken into account $7,8,20,28$.

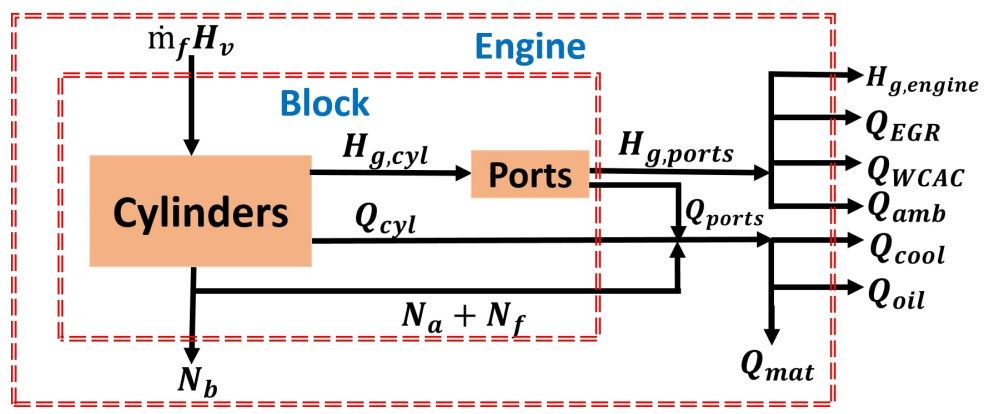

Figure 4. Energy distribution

The energy flows entering the engine are the sensible enthalpy of air, $\dot{m}_{a} h_{a}^{\text {sens }}$, the sensible enthalpy of fuel, $\dot{m}_{f} h_{f}^{\text {sens }}$ and the chemical energy of the fuel with its heating 
value $\dot{m}_{f} H_{v}$. The outlet energy flows are the brake power, $N_{b}$, the heat flow to the coolant, $\dot{Q}_{\text {cool }}$, the flow of sensible enthalpies of the exhaust gases $\dot{m}_{\text {exh }} h_{e x h}$, the heat rejection to oil, $\dot{Q}_{o i l}$ (which at the end will be rejected to coolant in the oil exchanger), the heat cumulated in the engine structure, $\dot{Q}_{\text {mat }}$, the heat rejection in the intercooler, $\dot{Q}_{W C A C}$, the heat rejection in the EGR heat exchangers, $\dot{Q}_{L P E G R}$ and $\dot{Q}_{H P E G R}$ (for the sake of rigor there is not a heat exchanger for the HPEGR but the block itself acts as a cooler when the HPEGR passes through it), which are also considered explicitely even though they are finally cooled by the engine coolant, the heat from the external walls of the engine to the ambient, considered through the heat rejection in the pipes, $\dot{Q}_{\text {pipes }}$ and turbo case, $\dot{Q}_{\text {turbo-amb }}$ and finally, the enthalpy flow of blow-by losses, $H_{b b}{ }^{7,8,28}$.

In order to perform the detailed analysis of energy repartition, some energy terms are rearranged and the first law of thermodynamics can be expressed as:

$$
\begin{aligned}
\dot{m}_{f} H_{v}= & N_{b}+N_{a}+H_{e x h}+\dot{Q}_{c o o l}+\dot{Q}_{o i l}+\dot{Q}_{m a t}+\dot{Q}_{W C A C}+\dot{Q}_{H P E G R} \\
& +\dot{Q}_{L P E G R}+\dot{Q}_{\text {pipes }}+H_{b b}+\dot{Q}_{\text {turbo-amb }}
\end{aligned}
$$

The description of the terms and how they are determined in the GEB analysis is the following:

- $\dot{m}_{f} H_{v}$ is the chemical power of the fuel. It is determined from the measurement of fuel mass flow $\dot{m}_{f}$ (which is imposed in VEMOD) and its heating value, $H_{v}$. The heating value of diesel fuel used in this work is $42.92 \mathrm{MJ} / \mathrm{kg}$.

- $N_{b}$ is the brake power is determined by VEMOD, by subtracting mechanical losses from indicated power.

- $N_{a}$ is power to run the auxiliaries elements that is determined in VEMOD with the models of the fuel, coolant and oil pumps ${ }^{29}$.

- $H_{\text {exh }}$ is the net flow of the gases sensible enthalpy determined through balance between incoming and outgoing enthalpy flows.

$$
\begin{gathered}
H_{e x h} \simeq \dot{m}_{e x h} h_{e x h}^{\text {sens }}-\dot{m}_{a} h_{a}^{\text {sens }}-\dot{m}_{f} h_{f}^{\text {sens }} \\
\dot{m}_{e x h}=\dot{m}_{a}+\dot{m}_{f}+\dot{m}_{b b}
\end{gathered}
$$

where $\dot{m}_{a}, \dot{m}_{f}, \dot{m}_{b b}$ and $\dot{m}_{e x h}$ are the intake air, injected fuel, blow by flow rate and exhaust mass flow rates. $h_{a}^{\text {sens }}, h_{\text {fuel }}^{\text {sens }}, h_{\text {exh }}^{\text {sens }}$ are the specific sensible enthalpies of air, fuel and exhaust gases, determined from the corresponding specific heats.

- $H_{b b}$ is the net flow of blow-by sensible enthalpy. It is determined by the balance between incoming and outgoing blow-by enthalpy flows. The final expression for 
net flow of blow-by sensible enthalpy is:

$$
H_{b b}=\dot{m}_{b b} h_{b b}^{e x h}-\dot{m}_{a}^{b b} h_{a}^{s e n s}-\dot{m}_{f}^{b b} h_{f}^{s e n s}
$$

where $\dot{m}_{b b}$ is the mass flow leakage due to blow-by. $h_{b b}^{\text {exh }}, h_{a}^{\text {sens }}, h_{f}^{\text {sens }}$ are the sensible enthalpies corresponding to blow.by leakage, fresh air and fuel.

- $\dot{Q}_{\text {cool }}$ is the total heat transfer to the coolant that is obtained by means of a lumped conductance model ${ }^{30,31}$. It is mainly due to the heat transfer from the chamber, but the engine coolant refrigerates the complete engine block, which also includes heat transfer from engine ports, $\dot{Q}_{\text {ports }}$. As commented, specific terms for oil heat rejection and EGR are independently considered.

- $\dot{Q}_{\text {oil }}$ is the heat rejection to the oil in the engine block and turbocharger. As in case of $\dot{Q}_{c o o l}$, it is obtained by means of two lumped conductance models, the first considers the engine block and second the turbo ${ }^{30}$. It is mainly due to the heat rejection from the chamber to piston, but also friction and in lower extent turbo cooling has a relevant role.

- $\dot{Q}_{\text {mat }}$ is the heat cumulated in engine structure during the transient evolution. It is obtained in VEMOD taking into account the thermal capacity of the whole engine structure.

- $\dot{Q}_{W C A C}$ is the heat rejection in the intercooler. It is determined from the air mass flow and its temperature variation.

$$
\dot{Q}_{W C A C}=\dot{m}_{w c a c} c_{p, a}\left(T_{a, \text { out }}-T_{a, \text { in }}\right)
$$

where $T_{a, \text { in }}$ and $T_{a, \text { out }}$ are the temperatures at inlet and outlet of the intercooler, and $c_{p, a}$ is the specific heat of the air.

- $\dot{Q}_{H P E G R}$ and $\dot{Q}_{L P E G R}$ are the heat transfers in the high pressure and low presure EGR heat exchangers. They are obtained in VEMOD using the following expression and difference of temperatures of the fluid at the inlet and outlet of the heat exchanger.

$$
\dot{Q}_{E G R}=\dot{m}_{E G R} c_{p, E G R}\left(T_{E G R, \text { out }}-T_{E G R, \text { in }}\right)
$$

where $\dot{m}_{E G R}$ is the EGR mass flow, $T_{E G R \text {,in }}$ and $T_{E G R \text {,out }}$ are the temperatures at inlet and outlet of the exchanger, and $c_{p, E G R}$ is the specific heat of the fluid.

- $\dot{Q}_{\text {turbo-amb }}$ is the heat rejected from turbocharger to ambient. It is determined in VEMOD using a lumped conductance model in which the ambient is a node used as boundary conditions ${ }^{30,31}$.

- $\dot{Q}_{\text {pipes }}$ is the heat rejection to the ambient in the pipes. It is obtained with the help of simple lumped model, considering gas inside the pipes and ambient air as boundary conditions. 


\section{Model calibration and validation}

\section{Calibration in stationary conditions}

In order to proceed with the analysis of energy balance, the calibration of the Virtual Engine, VEMOD, was previously performed. The calibration includes the determination of the fitting constants of different sub-models of VEMOD. Thus, it is necessary to determine the calibration constants of the heat transfer, combustion and mechanical losses models. Moreover, it is also necessary to accurately determine some engine characteristics such as the static and dynamic compression ratios (VEMOD includes a simple deformation model). The calibration was performed using motoring and combustion tests in stationary conditions as detailed in Table 3.

Motoring test was used to adjust engine uncertainties and to perform an initial convective heat transfer tuning ${ }^{26}$. Later, the warm and cold test indicated in Table 3, covering the complete engine map, were used for commissioning the rest of sub-models.

In short, the tool calibration includes the following points:

- Real compression ratio, deformations model and in-cylinder heat transfer model calibration was performed by means of an in house developed methodology in which a combination of experimental and simulated in-cylinder cycles are used. The complete description can be found in ${ }^{26}$. The heat transfer model refinement method is described in ${ }^{28}$.

- The injector model was calibrated with a complete experimental matrix in an injector test rig. The calibration of the injection rate model was carried out following the methodology detailed in ${ }^{32}$.

- The combustion model calibration was performed after the heat transfer model calibration, which affects the experimental heat release (main input for the combustion model). The calibration of the combustion model includes the determination of the different constants of the three sub-models: ignition delay, premixed and diffusion sub-models. The criterion for the determination of the models constant was to minimize the difference between the experimental heat release and the simulated one.

- Even though out of the scope of this work, aftertreatment models were calibrated (and validated) in stand-alone executions. The detailed description of the complete process and the experimental condition used for the calibration can be found at ${ }^{33}$.

- The friction model calibration, aimed at obtaining an accurate prediction of the brake efficiency, was performed with stationary operating points in the complete engine map both at cold and warm conditions. The methodology is described at ${ }^{34}$.

Following, some key results that allow characterizing the model performance are shown.

Figure 5 shows the experimental and modeled in-cylinder pressure and heat release at engine speed of $2500 \mathrm{rpm}$ at different loads $(25 \%, 50 \%, 75 \%$ and $100 \%)$. The dotted 

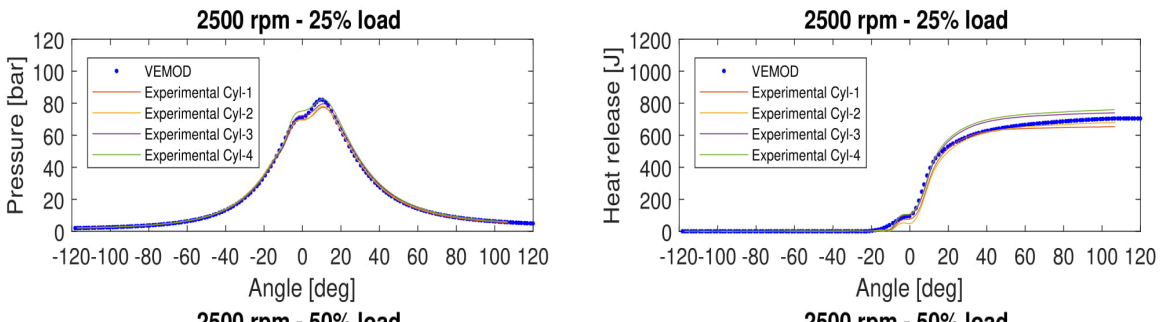

2500 rpm - 50\% load

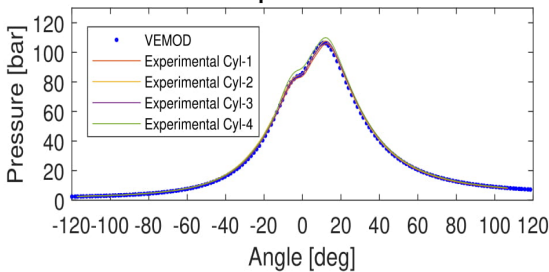

$2500 \mathrm{rpm}-\mathbf{5 0} \%$ load

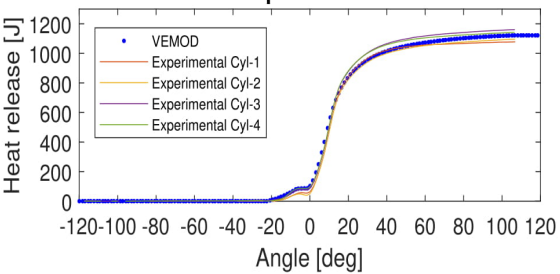

$2500 \mathrm{rpm}$ - $\mathbf{7 5} \%$ load

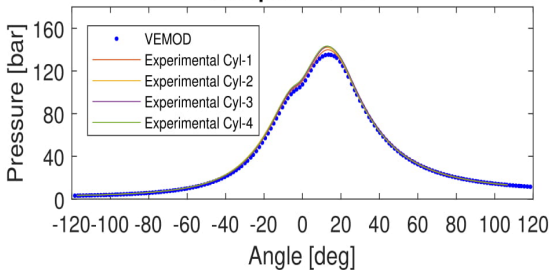

$2500 \mathrm{rpm}-\mathbf{7 5} \%$ load

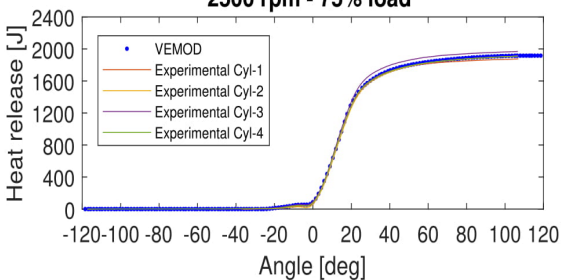

$2500 \mathrm{rpm}-100 \%$ load

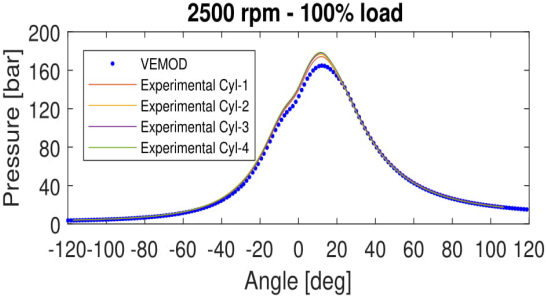

$2500 \mathrm{rpm}-100 \%$ load

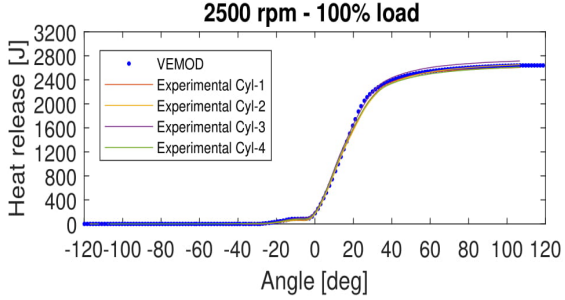

Figure 5. In-cylinder pressure and Heat release at different loads in stationary

lines represent the modeled values of VEMOD for one cylinder (no relevant dispersion between cylinders exists) and the solid lines represent the experimental values of the four cylinders. As it can be seen, the pressure and heat release evolutions are quite well predicted even though it can be identified a slight trend to underestimate the combustion velocity, especially at high load conditions. Also an overestimation of the blow-by in these conditions high loads contribute to underestimate the pressure peak. In any case, the global performance is good with slight uncertainty. 

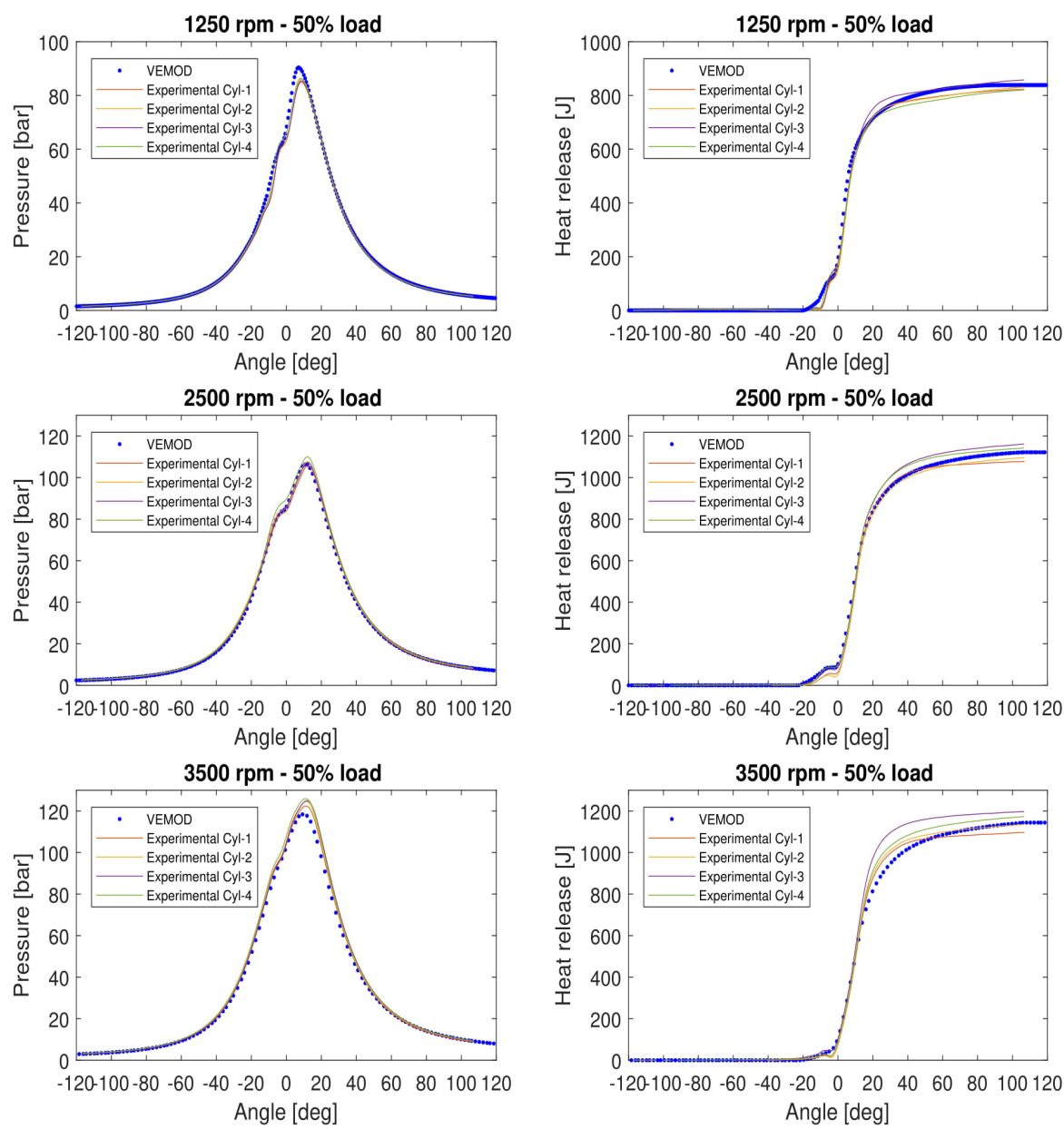

Figure 6. Pressure and Heat release at different speeds at $50 \%$ load in stationary

Figure 6 represents the pressure and heat release at engine speeds of $1250 \mathrm{rpm}, 2500$ rpm and $3500 \mathrm{rpm}$ and $50 \%$ load. As it can be seen, the modeled results shows a good global agreement with experimental data. However, the modeled heat release are slightly lower than the experimental ones at high speed and load, even though at the end, the simulated heat release is in the range of experimental dispersion. The reason for the slightly poorer performance at high speed and load is due to the fact that the priority was put on the low-mid ranges because they are critical for the test cycle simulation, 
main objective of the work. In any case, as shown in the next paragraph, if the analysis is extended to other key outputs, global performance of the model is good.

It has to be highlighted that, due to the physical approach of the tool, no correction or lookup table is used in any sub-model to take into account specific characteristic of the operating conditions.

Figure 7, Figure 8 and Figure 9 represents the IMEP, turbine inlet temperature and coolant temperature for all the selected points in steady-state at various engine speeds and loads. In the case of IMEP, the mean relative error is about $2 \%$, for turbine inlet temperature the mean relative error is $1.5 \%$ and in the case of coolant temperature, the mean relative error is $0.5 \%$.

For the sake of brevity, other variables that will be later shown in transient, have been omitted, but their global performance is similar to the shown variables, thus brake mean error is $4.5 \%$, turbine outlet temperature is $2.5 \%$ and oil temperature is $1.5 \%$.

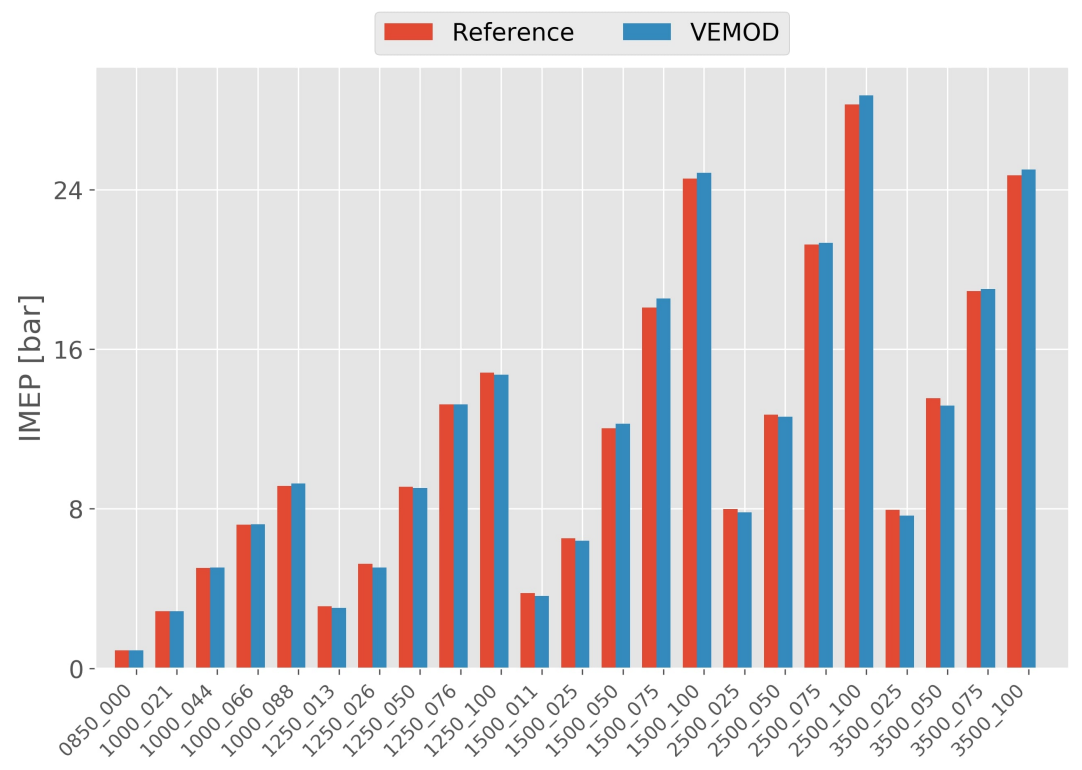

Figure 7. IMEP at different speeds and load in stationary conditions 


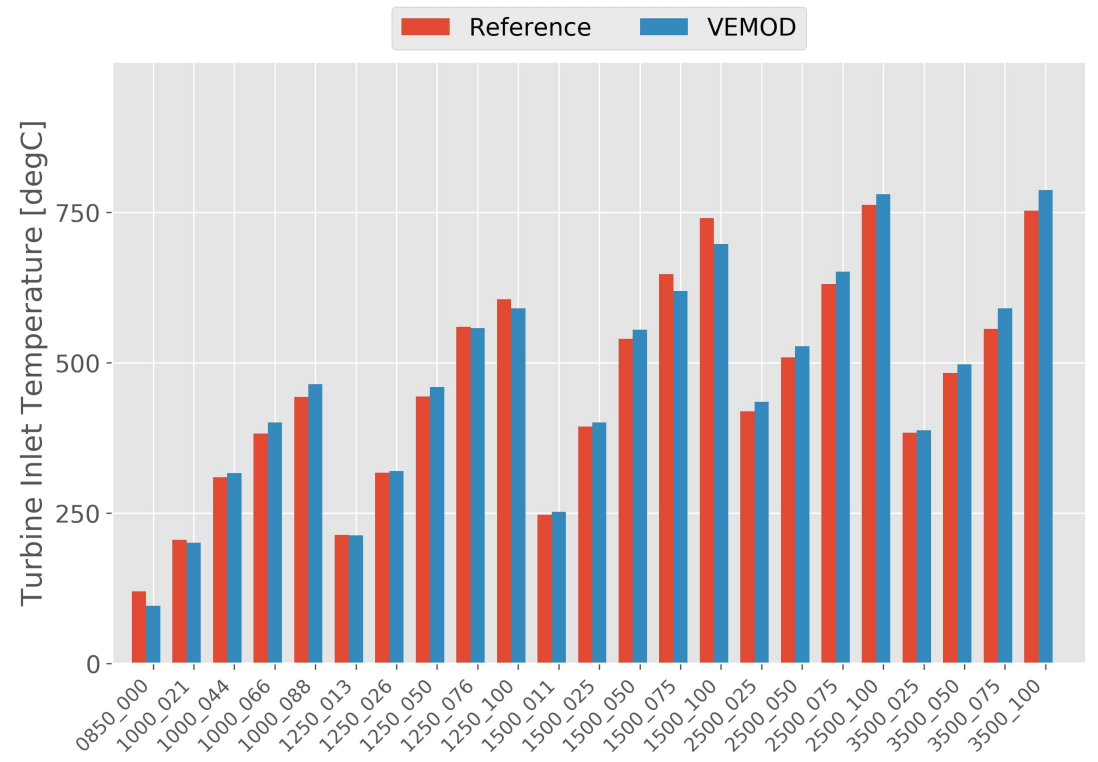

Figure 8. Turbine inlet temperature at different speeds and load in stationary conditions

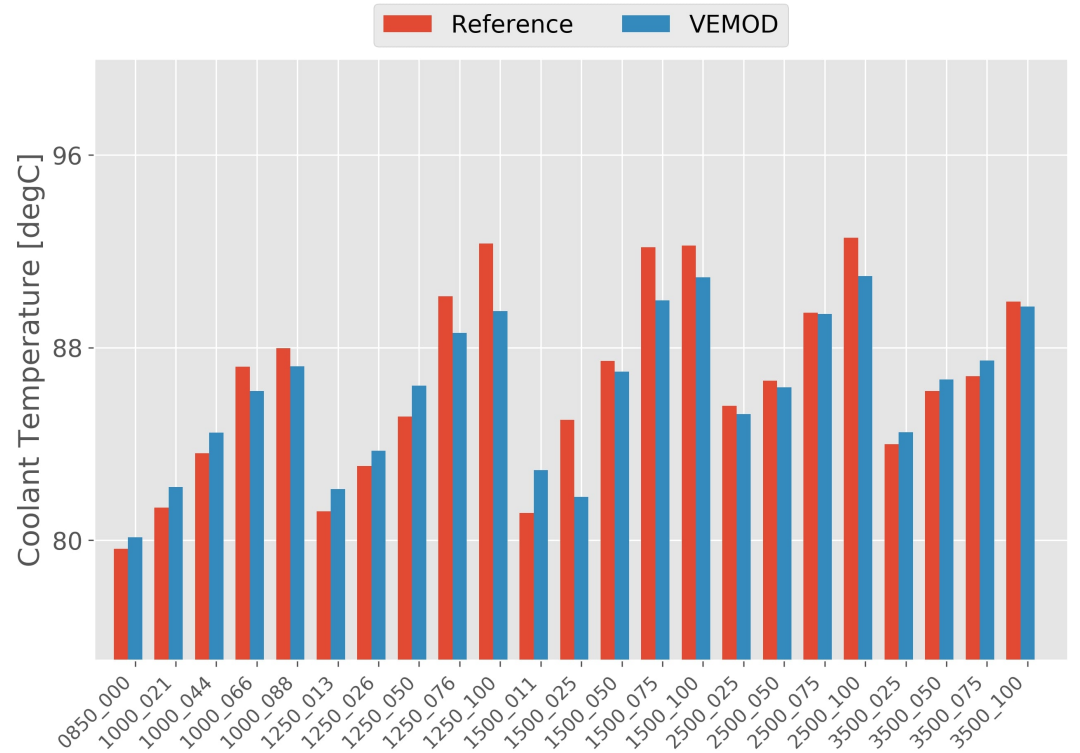

Figure 9. Coolant temperature at different speeds and load in stationary conditions 


\section{Transient validation}

Before facing the energy balance in transient operation it is necessary to ensure the good performance of the model, also in this conditions. For this purpose the experimental speed, injection settings, air demand and boost pressure are set as targets for the control system during the WLTC. The performance is validated with the different variables but the four most relevant will be shown: torque, turbine outlet temperature, coolant and oil temperatures. In order to facilitate the comprehension, the engine speed and load during the WLTC is shown in Figure 10.

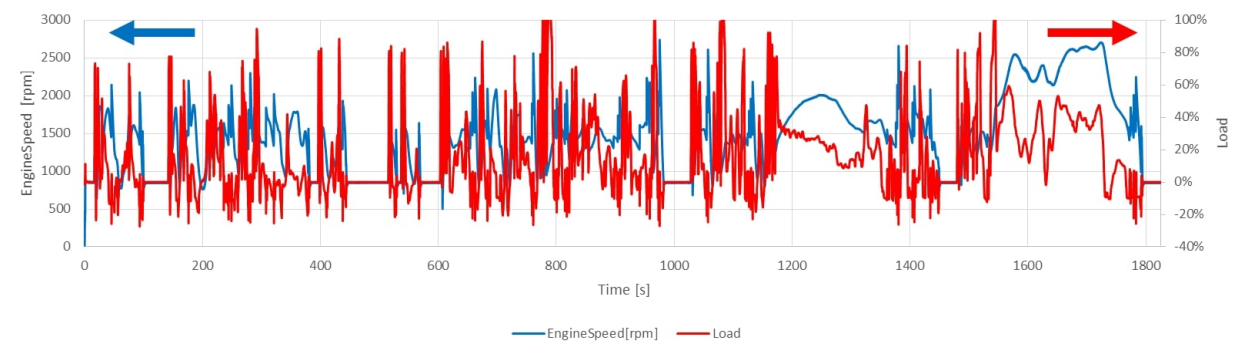

Figure 10. Engine speed and load

Brake torque
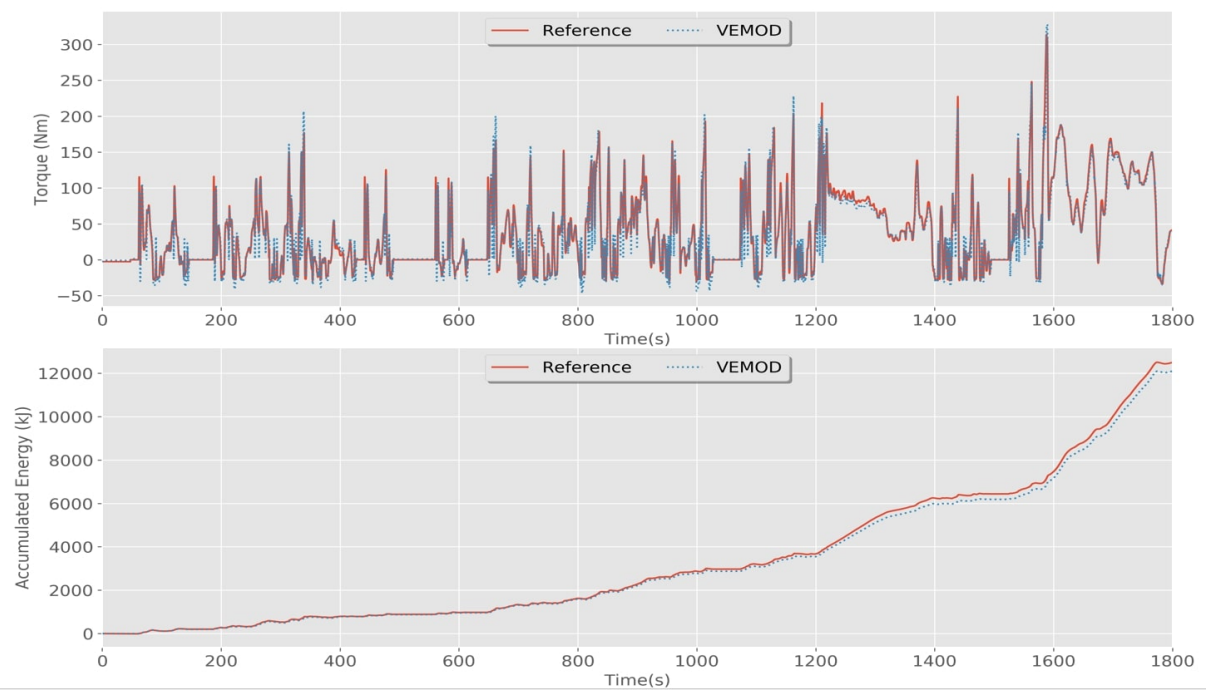

Figure 11. Brake torque and brake power in transient at cold conditions

Figure 11 shows the torque and cumulated brake power during a complete WLTC, starting at $20^{\circ} \mathrm{C}$. It can be seen that the variations in the torque are well followed by the 
model, in particular during the fast load changes. The model prediction has a mean error of about $8 \mathrm{Nm}$ (mean relative error is about 5\%), having $92 \%$ of the total points an error below $9 \mathrm{Nm}$. Even though some discrepancy can be observed at the low load variations, the cumulative effect during the complete cycle is only $2.5 \%$.

Turbine outlet temperature

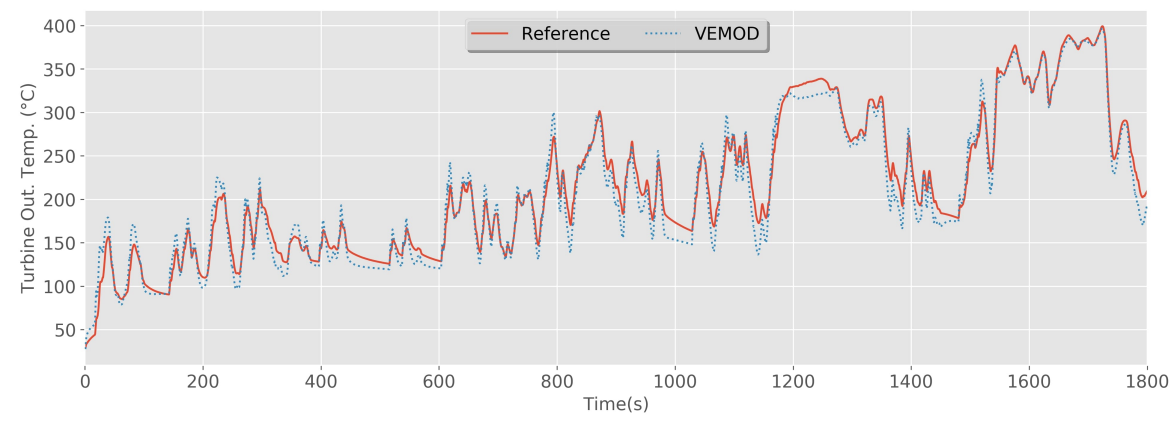

Figure 12. Turbine outlet temperature in transient at cold conditions

Turbine outlet temperature, is a key variable for the aftertreatment operation. It is plotted in Figure 12 and, as can be seen, it shows a good model response to variations, however, in general, it has a higher model peak values. The mean error for the turbine outlet temperature is $8^{\circ} \mathrm{C}(2 \%)$. Even though the prediction of the instantaneous temperature evolution can be improved, $90 \%$ of the points present an error below $12^{\circ} \mathrm{C}$. In any case, the global performance of the outlet temperature ensures that the exhaust enthalpy analysis will be accurate enough for the Global Energy Balance.

Coolant temperature and oil temperature

Figure 13 and Figure 14 shows the coolant and oil temperature in transient conditions. The mean error of the coolant temperature is $3.5^{\circ} \mathrm{C}$ and the relative error is about $2 \%$. Whereas, the mean error of the oil temperature is $2^{\circ} \mathrm{C}$ and the relative error is about $1 \%$. Also, $82 \%$ of points show relative error below $5^{\circ} \mathrm{C}$ for both coolant and oil temperatures, which shows a good model prediction. The good performance of the coolant and oil temperatures allow ensuring that the heat rejection, key term in the energy balance, is well predicted by the model. The results in the warmed conditions have been omitted for the sake of brevity. but, they are pretty similar to those shown.

\section{GEB analysis}

After the validation of VEMOD, the GEB is carried out. Before starting with the analysis, it is interesting to provide a preliminary discussion. When performing the energy balance 


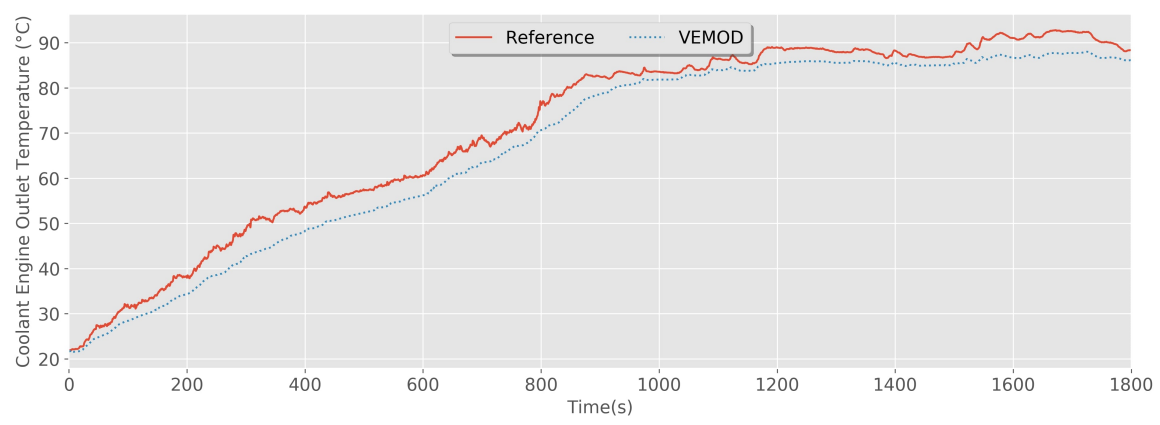

Figure 13. Coolant temperature in transient at cold conditions

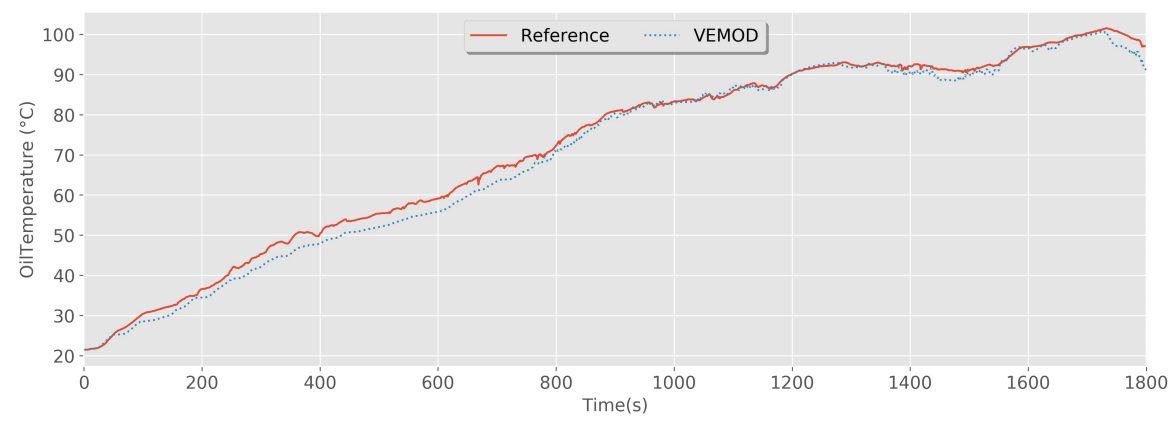

Figure 14. Oil temperature in transient at cold conditions

in stationary conditions, there is no energy accumulation in the engine. Thus, if the energy split is performed using mean variables that characterize the system state (such as fluid temperatures and mass flows) there wouldn't be any unbalance, except that due to the experimental uncertainty ${ }^{26}$ or numerical error. This can be applied to whichever system boundaries considered (only engine block, complete engine including pipes, turbo, exchangers, etc.). However in transient operation, two important phenomena affecting the energy balance must be considered.

On the one hand there is an energy accumulation in different masses of the system, in particular in the metallic elements of the block, pipes, turbo etc. being the first one, the most important. Also there is heat accumulation in the coolant and oil. The accumulation in the metallic element is explicitly considered, while the fluid accumulation is implicitly considered because the heat rejection to coolant and oil will be internally used for both fluid heating and heat rejection in the exchangers. 
On the other hand there is an important issue due to the "delay" of the mass and energy transfer at different engine position due to the distance of the elements in the gas path. This leads to an apparent unbalance depending on the system boundary limits considered, thus if only cylinder and ports are considered, the system response in the ports is almost instantaneous and the exhaust temperature changes cycle to cycle. However, if the complete gas pipes including high pressure and low pressure lines, turbo, exchanger, etc., are considered, there is an apparent inconsistency between the instantaneous heat release in the cylinder and the addition of the rest of energy terms. In fact this effect can be seen as an energy accumulation effect in the gas along the complete engine. When the enthalpy flow is integrated along a long period, this unbalance tends to become negligible. In order to perform a complete analysis two engine boundary limits are going to be considered for the cold conditions: on the one hand the engine block, on the other hand the complete engine. The "delay" effect will be clearly seen in the second one.

It is important to highlight that during the transient operation the instantaneous terms fluctuate fast (for the sake of rigor, take into account that terms described in 'Global Energy Balance (GEB) description' section are instantaneous power terms), thus being impossible to identify properly the relevant trends. Thus, the energy balance will be plotted in relative cumulated terms and hence each term will be finally computed as:

$$
E_{i}(t)=\frac{\int_{0}^{t} \dot{E}_{i}(t) \cdot d t}{\int_{0}^{t} \dot{m}_{f}(t) \cdot H_{v} \cdot d t} \cdot 100
$$

where $E_{i}(t)$ is the relative cumulated term at the instant $t, \dot{E}_{i}(t)$ is each of the instantaneous power terms described and $m_{i}(t) \cdot H_{v}$ is the instantaneous injected fuel energy.

\section{Cold conditions}

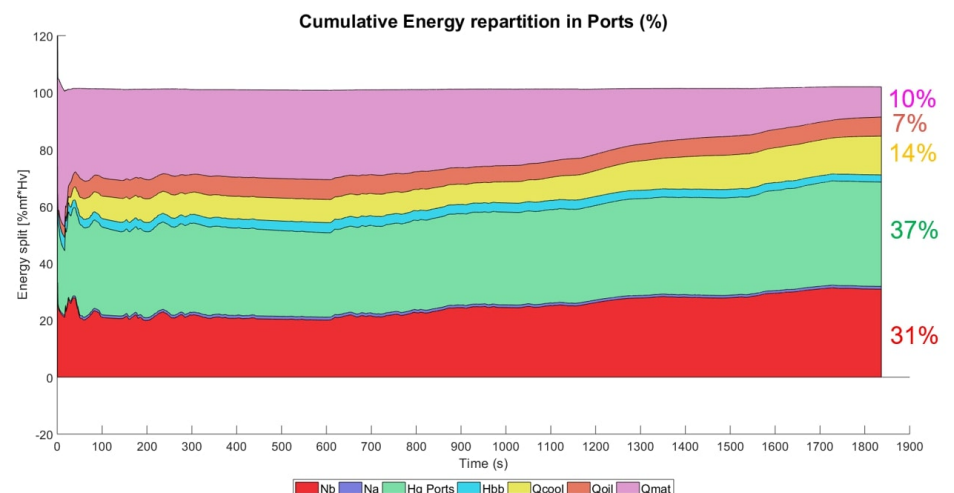

Figure 15. Cumulative energy repartition in engine block in WLTC at cold conditions 
Figure 15 shows the energy balance considering the engine block (cylinders and ports) at cold conditions. As it can be seen, the fluctuations of the energy distribution are higher at the beginning and becomes smoother as the time increases. The reason is that the fast load variation at the beginning leads to modify importantly the numerator (and in some extent also the denominator) of Equation 7. But later, fast transient changes have a lower effect on the accumulated energy terms and thus they stabilize gradually. As explained, it can be seen that in this case there is an almost perfect agreement between the input fuel energy and the addition of the exhaust energy, brake power, auxiliary power, heat transfer to coolant, oil and cumulated heat in the material. As shown, the usual energy distribution of $30 \%-35 \%$ brake power, $60 \%-70 \%$ heat rejected and exhaust enthalpy can be seen at the end of the cycle, but there are important variations during the WLTC evolution, as the different energy terms tends to stabilize gradually with time. At the end of the cycle, brake power, $N_{b}$ constitutes about $31 \%$ of total fuel energy output of engine. However, it is clearly lower during initial operation because of the high mechanical losses and heat rejection, but mainly due to the high amount of energy dedicated to heat the engine, as discussed below.

It can be observed that when the operating conditions of the engine cover higher loads, during the second part of the cycle, the weight of the brake energy increases up to the final values. Heat rejected to coolant, oil and material heating contribute about $25 \%$ of total energy output. The evolution of the heat rejection to coolant and oil along the cycle is quite stable, however it must be analyzed in combination with the energy used to heat the block $\left(\dot{Q}_{m a t}\right)$. Thus, it can be seen that at the beginning this is the main term, with an initial weight of about $50 \%$. Due to the low temperature of metal, most of the heat rejected to the cylinder walls (also very high at the beginning due to cold conditions and low load) is used to increase the block temperature, thus reducing the heat rejected to coolant and oil. As the metal and fluids get hotter the average power used to heat the block tends to become zero and thus the fraction of accumulated energy also diminishes. Simultaneously there is a trend to slightly increase the heat rejected to coolant $\left(\dot{Q}_{c o o l}\right)$ and oil $\left(\dot{Q}_{o i l}\right)$. It can be identified the effect of the thermostat opening around 800 seconds, when a fast reduction in $\dot{Q}_{\text {mat }}$ begins and there is an increase of $\dot{Q}_{\text {cool }}$. Regarding the heat repartition towards the oil and coolant circuits, $\dot{Q}_{o i l}$ is higher at the first half of the cycle due to the higher importance of the friction losses at the beginning, mainly due to the lower oil temperature, as later discussed. Progressively, the cumulated $\dot{Q}_{\text {cool }}$ fraction increases in the second half of the cycle, becoming more than two times higher than the $\dot{Q}_{\text {oil }}$ at the end of WLTC (14\% vs 7\%).

The third main term, along with brake energy and heat rejection, is the exhaust enthalpy flow, $H_{g, p o r t s}$ which contributes about $37 \%$ of the total cumulated energy at the end of the WLTC. It is quite stable along the complete cycle with a global trend to increase, mainly in the second half of the WLTC where higher loads and speeds are reached ${ }^{28}$. Two small terms complete the balance of the block: The energy to drive the auxiliary systems, which are lower to $1 \%$ during all the cycle and the enthalpy losses due to the blow-by leakage. This term diminishes gradually from $3 \%$ to $2 \%$, being higher at the beginning due to the higher blow-by leakage flow (in comparison with the trapped mass) at low load and speed. 


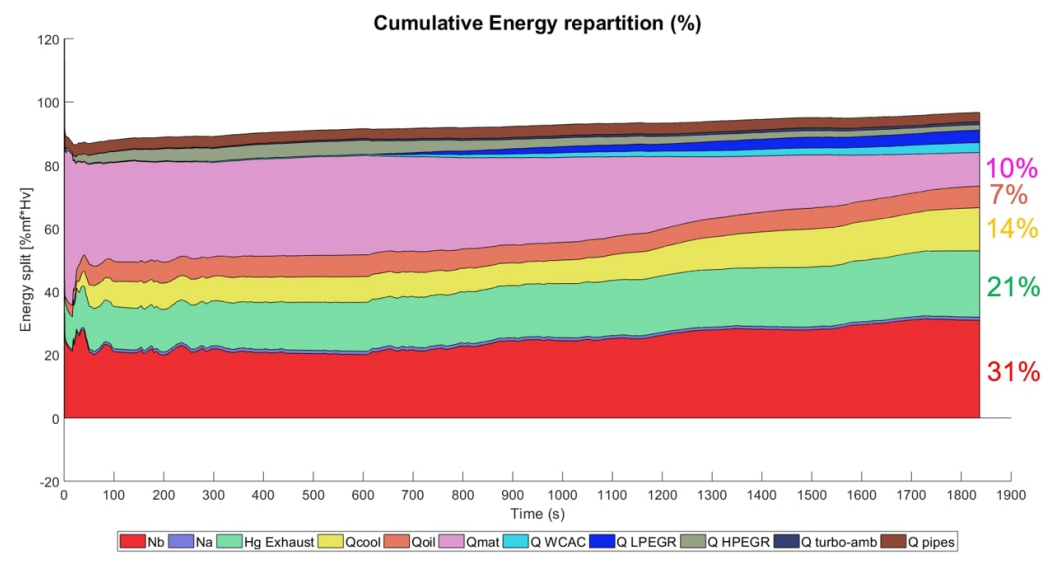

Figure 16. Total cumulative energy repartition in WLTC at cold conditions

Figure 16 shows the energy balance considering the entire engine during WLTC starting at $20^{\circ} \mathrm{C}$ including gas path (high and low pressure EGR lines, turbo, etc.), between inlet (from ambient) to exhaust. Unlike in Figure 15 , there is an apparent unbalance at the beginning of the cycle, diminishing progressively. As discussed, this can be explained by the delay effect in the calculation of the enthalpy flows due to the physical non-synchronize phenomena in the pipes and the in-cylinder conditions. Thus there is a lag of energy at the beginning, which diminishes as the time increases and tends to be negligible at the end of the WLTC.

When the complete engine is considered, extra energy terms like heat rejected from high pressure and low pressure EGR, WCAC (intercooler) and to ambient are included in GEB. The brake power, $N_{b}$ and the heat rejection to coolant are the same as in the block (shown in Figure 15 ) because the EGR exchangers that are cooled by the block coolant has been considered separately. Heat rejection to oil is slightly higher due to the cooling effect of the turbocharger, being $7.5 \%$ at the end, only about $0.5 \%$ higher than in the previous analysis. Also auxiliaries are the same, while blow-by term is not explicitly considered as the blow-by mass flow is recirculated to the intake. This way, main changes are related to exhaust enthalpy flow and heat rejection in the exchangers.

The net exhaust enthalpy, $H_{g, \text { exhaust }}$ (calculated between engine intake and downstream the low pressure EGR pipe), contributes about $21 \%$ of total engine energy output at the end of the cycle. The difference with respect to $H_{g, \text { ports }}$ (about 16\%) is due to the heat rejection in the intercooler, EGR exchangers and finally turbo and pipes to ambient. Cumulated heat rejected to the intercooler is about $3 \% \dot{m}_{f} H_{v}$, being negligible until 500 seconds of operation because of the small difference between the air temperature at the compressor outlet and the intercooler coolant. $6 \%$ of total energy is rejected from the HPEGR and LPEGR lines at the end of the cycle. During the 
initial operation, HPEGR loop, which promotes the increase of inlet temperature, is activated and LPEGR loop is used in the later transient operation, when the coolant temperature is hotter. About $3 \%$ of heat is rejected to ambient through turbocharger and pipes $\left(\dot{Q}_{t u r b o-a m b}\right.$ and $\left.\dot{Q}_{\text {pipes }}\right)$.

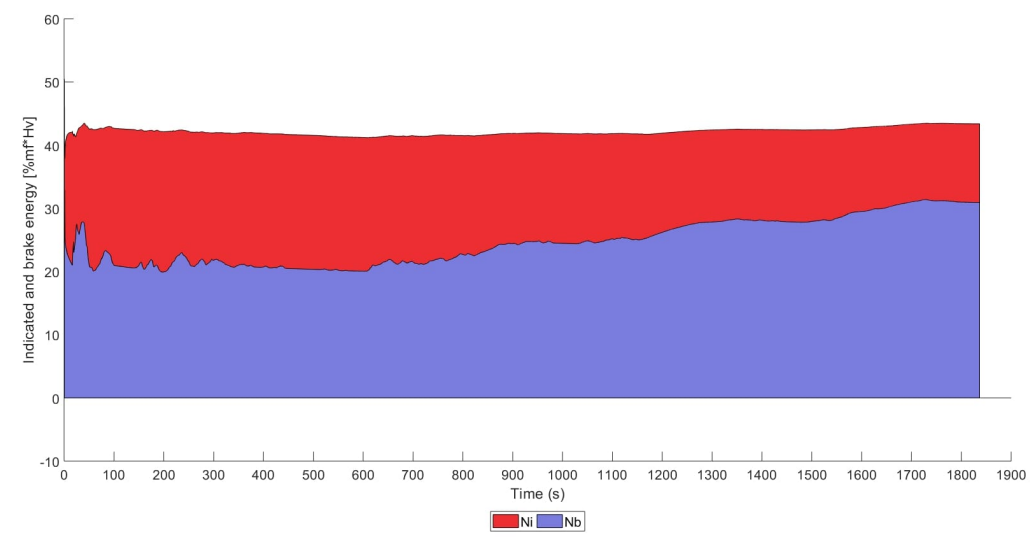

Figure 17. Cumulative indicated and brake energies in WLTC at cold conditions

In order to complete the analysis, Figure 17 shows the percentage of accumulated indicated and brake energies at cold conditions with respect to time. Indicated energy is around $44 \%$ of the total engine fuel energy during all the cycle, while brake power is $31 \%$ at the end, showing a clear trend to increase as the WLTC progresses. The lower values of brake energy at the beginning of the operation can be explained by the higher mechanical losses, as shown in Figure 18, because of low coolant and oil temperatures during the beginning of the operation, thus affecting the oil viscosity.

Figure 18 top shows that friction is the main component of the mechanical losses, being about $10 \%$ of the fuel energy at the end of the cycle, while pumping $\left(N_{p}\right)$ is about $2.5 \%$ and auxiliaries $\left(N_{a}\right)$ are $1 \%$. When analyzing the evolution along the cycle, it is also clear that there is a large reduction of the mechanical losses weight, in particular due to the friction, which at the end has a cumulative effect about 4 times lower than at the initial part of the WLTC.

As shown in the bottom of Figure 18 , main component of the friction is the piston friction, $N_{f r}$ piston, that is about two thirds of the total friction (7\% of the fuel energy), being the valve train the less important and the bearing friction the intermediate contribution. This friction repartition is consistent with some previous analysis performed in stationary conditions ${ }^{28}$.

\section{Warmed conditions}



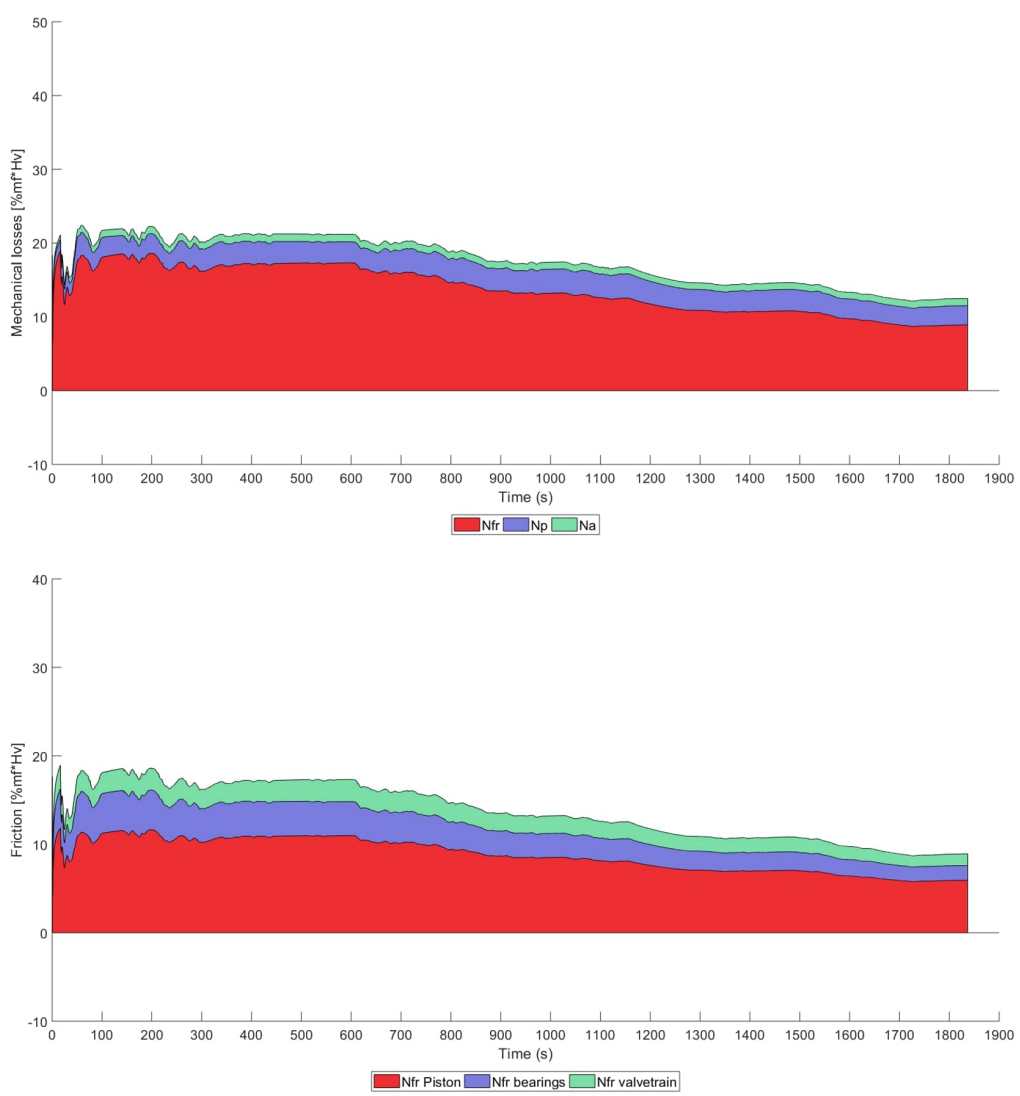

Figure 18. Cumulative mechanical losses (top) and friction split (bottom) in WLTC at cold conditions

As described, one of the purposes of this work is to compare the energy split starting at cold conditions with warmed engine, which energy balance considering the complete engine (including pipes, exchangers, turbo, etc., as in Figure 16) can be seen in Figure 19.

The most evident changes in comparison with results starting at cold conditions are related with heat transfer cumulated at the metal elements and the heat rejection to coolant and to oil. These changes are due to the change in the temperatures of the fluids and metal at the beginning of the cycle in comparison with cold condition. Thus, initially all the metal and fluid are around $21^{\circ} \mathrm{C}$ in cold start while in warmed conditions coolant is at $80^{\circ} \mathrm{C}$, oil is at $85^{\circ} \mathrm{C}$ ( these values were initialized at the model from experimental data ) while metal temperatures range from about $90^{\circ} \mathrm{C}$ at the liner to more than $100^{\circ} \mathrm{C}$ in some parts of the piston. Hence, at the beginning of the cycle the coolant temperature 


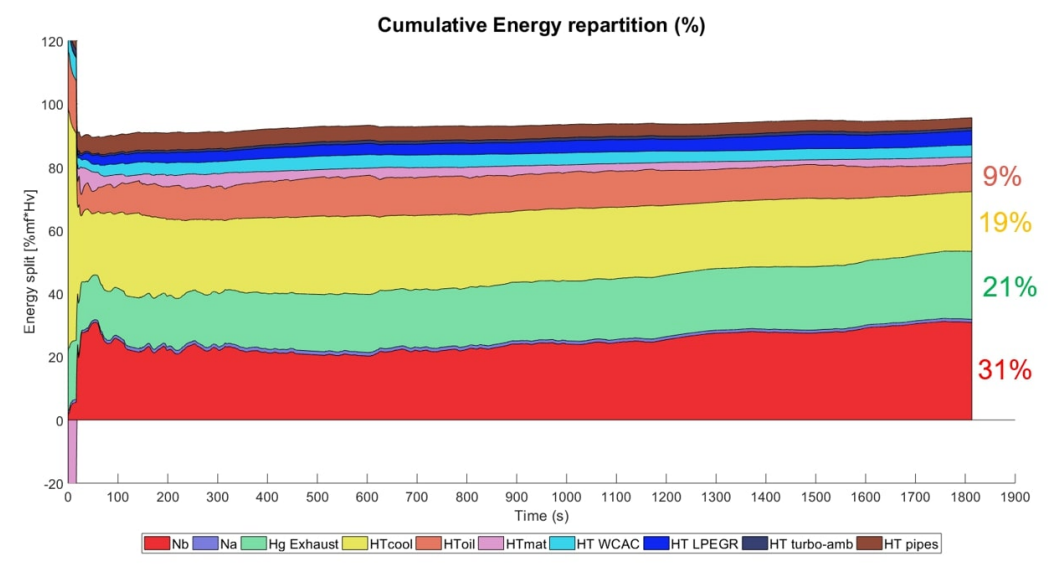

Figure 19. Total cumulative energy repartition in WLTC at warmed conditions

is higher to the thermostat opening temperature and the engine is rejecting heat to the radiator from the starting.

As shown in Figure 19, when the cycle starts there is a peak of heat coming from the metal which is rejected mainly to coolant and oil, due to their temperature difference. Later, after first idle of the WLTC (finishing about 17 seconds), instantaneous power rejection towards and from the metal parts start to oscillate (not shown) according to the operating conditions. As finally the engine reaches slightly different thermal condition in comparison with the initial ones (coolant temperature increases $4^{\circ} \mathrm{C}$ and oil $10^{\circ} \mathrm{C}$ ), the cumulated heat rejection to metal is not completely negligible, but only less than $2 \%$, much lower as in cold start.

Regarding coolant heat rejection, is much higher than in cold start at the beginning and it reaches a final value of $19 \%$. On the other hand, the heat rejection to oil does not show such an important peak at the beginning because, most of $\dot{Q}_{\text {mat }}$ is rejected to the coolant exchanger. As later discussed, the final cumulated values of the heat rejected to coolant and oil are higher than in cold conditions.

The rest of the terms in particular brake efficiency, heat rejection in the EGR coolers and intercooler, do not show an important variation. The only remarkable results are that in warmed condition the engine is running with low pressure EGR from the beginning (while in cold conditions the engine started with high pressure EGR), but the total fraction of heat rejected to the EGR coolers is similar. Also a slightly higher heat rejection from metal elements to ambient ( pipes, turbo) can be seen in warmed conditions during the initial part of the cycle, but at the end of the WLTC is similar.

The comparison of energy terms at the end of the WLTC in at warmed and cold conditions is shown in Figure 20. It can be seen that cumulated brake efficiency during cold conditions is slightly lower than warmed conditions, but the difference is only about 

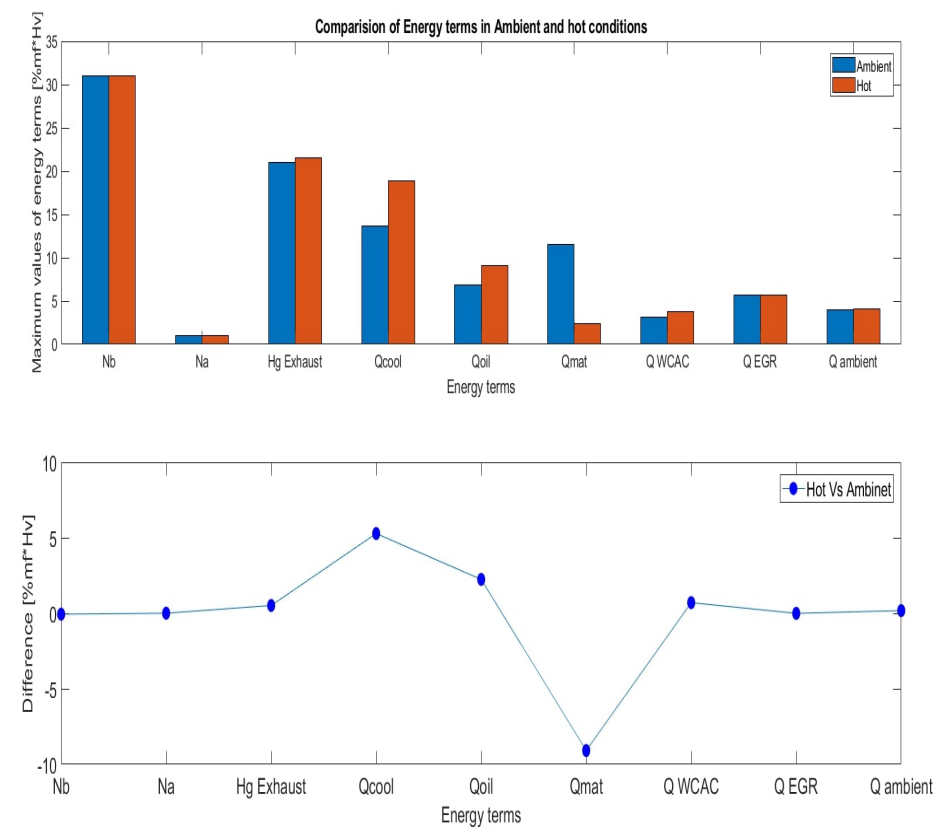

Figure 20. Comparison of energy terms in WLTC in cold and warmed conditions at the end of the cycle

$0.1 \%$. This benefit is achieved, thanks to the lower mechanical losses during warmed conditions, due to the high engine temperatures in warmed conditions in particular the oil temperature.

As it can be seen in Figure 21 global trend of the mechanical losses are similar to those shown in Figure 18, for cold conditions. However, some changes can be highlighted, the first is the slightly higher pumping work in warm condition mainly due to the change of EGR strategy at the beginning of the cycle; at the end of the cycle differences are small ( $3 \%$ vs $2.7 \%$ ). The second one is the lower friction, clearly seen in the half initial part of the WLTC, where the change in the fluid temperatures is relevant (at about $1000 \mathrm{~s}$, from the beginning engine temperatures are very similar in warmed and cold conditions). At 1000 seconds the reduction of the friction energy is about $2 \%$ of the fuel energy injected up to this instant in comparison with the cold conditions, as a result of the lower friction shown in Figure 22. However this difference is clearly reduced during the second part of the cycle, where oil temperatures are similar and the amount of fuel is much higher than in the first half (because of the higher load), hence, at the end of the cycle the friction differences are reduced to only $0.1 \%$. In any case, this reduction contributes to the slightly higher brake efficiency discussed. 


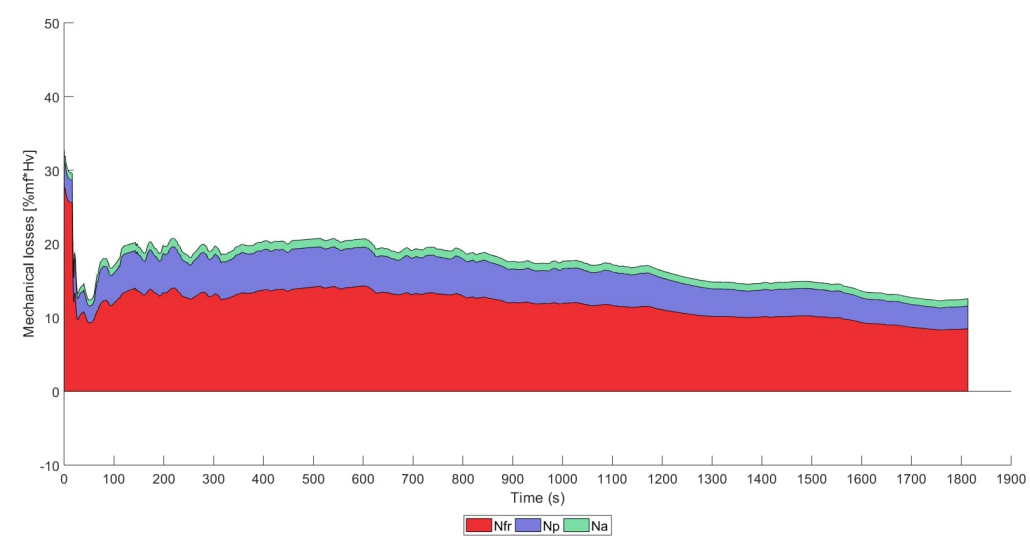

Figure 21. Cumulative mechanical losses in WLTC at warmed conditions

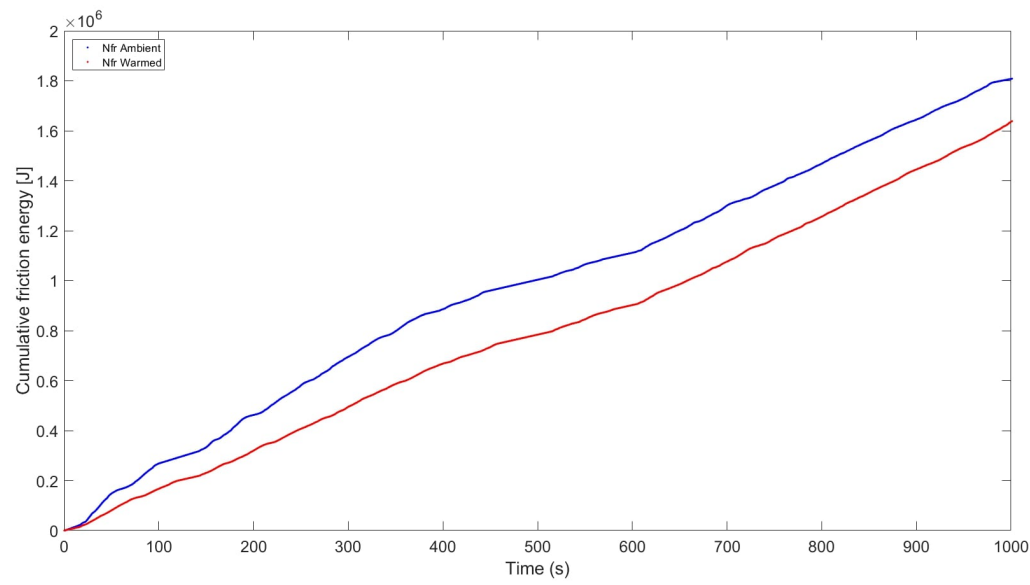

Figure 22. Cumulative friction energy during initial 1000 seconds at cold and warmed cycle

\section{Conclusions}

Simulation tool, VEMOD have been calibrated and validated using a 4-cylinder 1.6 L DI Diesel engine, before being used for the energy balance analysis. Good global performance has been found between the modeled and experimental results ( in stationary and transient ), when key outputs like pressure, heat released, turbine inlet/outlet temperatures, coolant temperature, oil temperatures and torque are considered.

A comprehensive analysis of the Global Energy Balance, using VEMOD has been done. This analysis contributes to understand the mechanism affecting the engine 
consumption and allows to assess the effect of different operating conditions on the global energy repartition during a WLTC.

The GEB analysis in cold conditions was performed, by considering two engine boundary limits (the engine block and the complete engine), where a "delay" effect due to the unsynchronized phenomena in the cylinders and far from them in the gas lines. This delay causes an unbalance at the beginning of the cycles that can reach more than $10 \%$ of the cumulated fuel energy, however, it diminishes progressively during the cycle. It was seen that $N_{b}, N_{a}, \dot{Q}_{\text {cool }}$ and $\dot{Q}_{o i l}$ are same when considering two boundary limits and the main changes are related to exhaust heat rejection in the exchangers and exhaust enthalpy flow, $H_{g \text {,exhaust }}$, whose difference with respect to $H_{g \text {,ports }}$ is about $16 \%$. This difference is due to the split of exhaust enthalpy in to several sub terms i.e., heat rejection in the turbo and pipes to ambient, the intercooler and EGR exchangers.

It has been shown that the lower values of brake energy at the beginning of the WLTC is promoted by the higher mechanical losses, which in turn were result of the higher oil viscosity because of lower coolant and oil temperatures. It has been found that the most important term in the mechanical losses is friction with a percentage of about $65 \%$ of the total mechanical losses and about $10 \%$ of the total fuel energy at the end of the WLTC, being the piston friction the most important with a weight of $60 \%$ of the total friction losses. A noticeable finding include the lower friction values in warmed conditions (difference is around $2 \%$ of the fuel energy) at 1000 seconds of the cycle. However, this difference diminishes by the end of the cycle with a final difference around $0.1 \%$.

The energy repartition considering the complete engine, at cold conditions was compared with warmed engine conditions. It has been seen that important changes take place in $\dot{Q}_{m a t}, \dot{Q}_{c o o l}$ and $\dot{Q}_{o i l}$ due to the different initial temperatures in cold and warmed conditions. It was seen that $\dot{Q}_{c o o l}$, which tends to increase when engine starting temperature increases, and $\dot{Q}_{o i l}$ are higher in warmed conditions (21\% vs $28 \%$ ) because the rejection to the exchanger take place from the beginning, while in the case of the cold starting the thermostat is closed during the initial part of the cycle and the heat rejected to coolant and oil is used to increase the fluid temperatures. With the decrease in initial temperature $\dot{Q}_{\text {mat }}$ tends to increase being $10 \%$ at the end of the WLTC in cold starting and negligible in warm starting. It was found that there is a minor effect of the ambient conditions on $N_{b}$ (difference is less than $1 \%$ ), $\dot{Q}_{W C A C}, \dot{Q}_{H P E G R}$ and $\dot{Q}_{L P E G R}$. Finally, it was seen that despite of few uncertainties like the "delay" effect, the model shows good performance with final cumulated unbalance of about $3 \%$ in both cold start and warmed conditions.

\section{Acknowledgments}

This research has been partially funded by the European Union's Horizon 2020 Framework Programme for research, technological development and demonstration under grant agreement 723976 ("DiePeR") and by the Spanish government under the grant agreement TRA2017-89894-R. The authors wish to thank Renault SAS, especially P. Mallet and E. Gaïffas, for supporting this research. 


\section{References}

1. Rakopoulos. Diesel Engine Transient Operation - Principles of Operation and Simulation Analysis. ISBN 9781848823747.

2. Rakopoulos CD, Giakoumis EG, Hountalas DT et al. The Effect of Various Dynamic, Thermodynamic and Design Parameters on the Performance of a Turbocharged Diesel Engine Operating under Transient Load Conditions. SAE Technical Paper Series 2010; 1(724). DOI: 10.4271/2004-01-0926.

3. European Parliament and Council of the European Union. Regulation (EC) No 852/2004 of the European Parliament and of the Council. Official Journal of the European Communities 2004; 2006(December 2006): 1-54. URL http: //eur-lex.europa.eu/LexUriServ/ LexUriServ.do?uri=0J:L:2004:139:0001:0054:en:PDF.

4. Martin J, Arnau F, Piqueras P et al. Development of an Integrated Virtual Engine Model to Simulate New Standard Testing Cycles. SAE Technical Paper Series 2018; 1: 1-17. DOI: 10.4271/2018-01-1413.

5. Payri F, Lopez JJ, Pla B et al. Assessing the Limits of Downsizing in Diesel Engines. SAE Technical Paper Series 2014; 1. DOI:10.4271/2014-32-0128.

6. Tauzia X, Maiboom A, Karaky H et al. Experimental analysis of the influence of coolant and oil temperature on combustion and emissions in an automotive diesel engine. International Journal of Engine Research 2019; 20(2): 247-260. DOI:10.1177/1468087417749391.

7. Payri F, Olmeda P, Martin J et al. A New Tool to Perform Global Energy Balances in DI Diesel Engines. SAE International Journal of Engines 2014; 7(1): 43-59. DOI: 10.4271/2014-01-0665.

8. Payri F, Martin J, Garcia A et al. Experimental and Theoretical Analysis of the Energy Balance in a DI Diesel Engine. SAE Technical Paper Series 2015; 1(x). DOI:10.4271/2015-01-1651.

9. Tauzia $X$ and Maiboom A. Experimental study of an automotive Diesel engine efficiency when running under stoichiometric conditions. Applied Energy 2013; 105: 116-124. DOI:10.1016/ j.apenergy.2012.12.034. URL http://dx.doi.org/10.1016/j.apenergy. 2012 . 12.034.

10. Abedin MJ, Masjuki HH, Kalam MA et al. Energy balance of internal combustion engines using alternative fuels. Renewable and Sustainable Energy Reviews 2013; 26: 20-33. DOI: 10.1016/j.rser.2013.05.049. URL http://dx.doi.org/10.1016/j.rser.2013. 05.049 .

11. Ajav EA, Singh B and Bhattacharya TK. Thermal balance of a single cylinder diesel engine operating on alternative fuels. Energy Conversion and Management 2000; 41(14): 1533-1541. DOI:10.1016/S0196-8904(99)00175-2.

12. Dimopoulos $\mathrm{P}$, Bach $\mathrm{C}$, Soltic $\mathrm{P}$ et al. Hydrogen-natural gas blends fuelling passenger car engines: Combustion, emissions and well-to-wheels assessment. International Journal of Hydrogen Energy 2008; 33(23): 7224-7236. DOI:10.1016/j.ijhydene.2008.07.012. URL http://dx.doi.org/10.1016/j.ijhydene.2008.07.012.

13. Taymaz I. An experimental study of energy balance in low heat rejection diesel engine. Energy 2006; 31(2-3): 364-371. DOI:10.1016/j.energy.2005.02.004. 
14. Smith LA, Preston WH, Dowd G et al. Application of a First Law Heat Balance Method to a Turbocharged Automotive Diesel Engine. SAE Technical Paper Series 2010; 1. DOI: 10.4271/2009-01-2744.

15. Olmeda P, Martín J, Novella $\mathrm{R}$ et al. Assessing the optimum combustion under constrained conditions. International Journal of Engine Research 2018; : 1-13DOI:10.1177/ 1468087418814086.

16. Durgun $\mathrm{O}$ and Şahin Z. Theoretical investigation of heat balance in direct injection (DI) diesel engines for neat diesel fuel and gasoline fumigation. Energy Conversion and Management 2009; 50(1): 43-51. DOI:10.1016/j.enconman.2008.09.007.

17. Jia M, Gingrich E, Wang $\mathrm{H}$ et al. Effect of combustion regime on in-cylinder heat transfer in internal combustion engines. International Journal of Engine Research 2016; 17(3): 331-346. DOI:10.1177/1468087415575647.

18. Jung D, Yong J, Choi H et al. Analysis of engine temperature and energy flow in diesel engine using engine thermal management, 2013. DOI:10.1007/s12206-012-1235-4.

19. Caresana F, Bilancia M and Bartolini CM. Numerical method for assessing the potential of smart engine thermal management: Application to a medium-upper segment passenger car. Applied Thermal Engineering 2011; 31(16): 3559-3568. DOI:10.1016/j.applthermaleng. 2011.07.017. URL http://dx.doi.org/10.1016/j.applthermaleng.2011. 07.017.

20. Payri F, López JJ, Martín J et al. Improvement and application of a methodology to perform the Global Energy Balance in internal combustion engines. Part 1: Global Energy Balance tool development and calibration. Energy 2018; 152: 666-681. DOI:10.1016/j.energy.2018. 03.118 .

21. Romero CA, Torregrosa A, Olmeda P et al. Energy Balance During the Warm-Up of a Diesel Engine. SAE Technical Paper Series 2014; 1. DOI:10.4271/2014-01-0676.

22. Arrègle $\mathrm{J}$, López $\mathrm{J}$, García $\mathrm{J}$ et al. Development of a zero-dimensional Diesel combustion model. Applied Thermal Engineering 2003; 23(11): 1319-1331. DOI:10.1016/ s1359-4311(03)00080-2.

23. Arrègle J, López JJ, García JM et al. Development of a zero-dimensional Diesel combustion model. Part 1: Analysis of the quasi-steady diffusion combustion phase. Applied Thermal Engineering 2003; 23(11): 1301-1317. DOI:10.1016/S1359-4311(03)00079-6.

24. Arrègle J, López JJ, Martín $\mathbf{J}$ et al. Development of a Mixing and Combustion ZeroDimensional Model for Diesel Engines. SAE Technical Paper Series 2010; 1(724). DOI: 10.4271/2006-01-1382.

25. Olmeda P, Martin J, Garcia A et al. Evaluation of EGR Effect on the Global Energy Balance of a High Speed DI Diesel Engine. SAE Technical Paper Series 2016; 1. DOI: 10.4271/2016-01-0646.

26. Benajes J, Olmeda P, Martín J et al. A new methodology for uncertainties characterization in combustion diagnosis and thermodynamic modelling. Applied Thermal Engineering 2014; 71(1): 389-399. DOI:10.1016/j.applthermaleng.2014.07.010.

27. Payri F, Margot X, Gil A et al. Computational Study of Heat Transfer to the Walls of a DI Diesel Engine. SAE Technical Paper Series 2010; 1(724). DOI:10.4271/2005-01-0210.

28. Payri F, Olmeda P, Martín J et al. Experimental analysis of the global energy balance in a di diesel engine. Applied Thermal Engineering 2015; 89(x): 545-557. DOI:10.1016/j. 
applthermaleng.2015.06.005.

29. Carreño Arango R. A comprehensive methodology to analyse the Global Energy Balance in Reciprocating Internal Combustion Engines. Doctoral thesis 2016; (September 2016). DOI: 10.4995/Thesis/10251/73069. URL http: / / hdl. handle. net/10251/73069.

30. Olmeda P, Dolz V, Arnau FJ et al. Determination of heat flows inside turbochargers by means of a one dimensional lumped model. Mathematical and Computer Modelling 2013; 57(7-8): 1847-1852. DOI:10.1016/j.mcm.2011.11.078. URL http://dx.doi.org/10.1016/ j.mcm.2011.11.078.

31. Torregrosa A, Olmeda P, Degraeuwe B et al. A concise wall temperature model for di Diesel engines. Applied Thermal Engineering 2006; 26(11-12): 1320-1327. DOI:10.1016/ j.applthermaleng.2005.10.021.

32. Payri R, Salvador FJ, Gimeno J et al. A new methodology for correcting the signal cumulative phenomenon on injection rate measurements. Experimental Techniques 2008; 32(1): 46-49. DOI:10.1111/j.1747-1567.2007.00188.x.

33. Payri F, Arnau FJ, Piqueras P et al. Lumped Approach for Flow-Through and Wall-Flow Monolithic Reactors Modelling for Real-Time Automotive Applications. SAE Technical Paper Series 2018; 1: 1-24. DOI:10.4271/2018-01-0954.

34. Tormos B, Martín J, Carreño R et al. A general model to evaluate mechanical losses and auxiliary energy consumption in reciprocating internal combustion engines. Tribology International 2018; 123(March): 161-179. DOI:10.1016/j.triboint.2018.03.007. URL https://doi.org/10.1016/j.triboint.2018.03.007. 
$-$ 